\title{
Operational Implementation of the AROME Model in the Tropics: Multiscale Validation of Rainfall Forecasts
}

\author{
Ghislain Faure, Philippe Chambon, and Pierre Brousseau \\ CNRM, Université de Toulouse, Météo-France, CNRS, Toulouse, France
}

(Manuscript received 4 October 2019, in final form 19 December 2019)

\begin{abstract}
Météo-France runs operationally, for the needs of several overseas regions in the tropical belt, five numerical weather prediction configurations, based on the convection-permitting model AROME and called the AROME-OM system. These configurations use the high-resolution model [Integrated Forecasting System (IFS)] from the European Centre for Medium-Range Weather Forecasts (ECMWF) for both initialization and lateral forcing. In this study, the performance of the AROME-OM system for rainfall forecasting is compared to the one of ECMWF IFS. The validation uses spatialized rainfall estimates over a 24-h time period at two time scales (daily and annual), from both satellite and ground-based instruments. It has been performed over a 10-month period and across five tropical domains. The intercomparison demonstrates consistent signals across domains and scales. The added value of the AROME-OM system compared to ECMWF IFS is shown for rain/no-rain discrimination and for rain accumulations larger than $10 \mathrm{~mm} \mathrm{day}^{-1}$. The AROME-OM system also shows a better ability to forecast realistic rain patterns over these tropical regions. The main weakness found is for an intermediate range of rain accumulations, from 1 to $10 \mathrm{~mm} \mathrm{day}^{-1}$, for which the ECMWF IFS forecasts slightly outperform the AROME-OM system forecasts.
\end{abstract}

\section{Introduction}

More than 2.5 million inhabitants live in French tropical overseas regions; for all but French Guiana, these regions are composed of islands, located in three different oceans: the North Atlantic, the southwest Indian, and the South Pacific. The needs of these territories for weather forecasting are large, from highimpact weather events to daily local effects, when the unstable tropical atmosphere meets steep orography. For almost 20 years, Météo-France has supported these regions by providing them dedicated numerical weather prediction (NWP) products, from a custom (unstretched) global model in 2002 to limited-area models (LAM) by 2006. Based on the ALADIN model (Termonia et al. 2018), this first generation of LAM was run at a resolution from 12 to $8 \mathrm{~km}$ during its period of operations (Montroty et al. 2008). A major upgrade of the NWP system for overseas regions occurred in February 2016, when the convection-permitting model Applications of Research to Operations at Mesoscale (AROME), with a 2.5-km horizontal resolution, was deployed operationally over these regions in replacement of ALADIN. This

Corresponding author: Ghislain Faure, ghislain.faure@meteo.fr step forward has been driven by the successful implementations in operations, during the last decade, of convection-permitting models over the United States (Weisman et al. 2008) and over western Europe (Lean et al. 2008; Baldauf et al. 2011; Seity et al. 2011). The more recent success of various convection-permitting models running operationally in the tropical belt (Bernardet et al. 2015; Woodhams et al. 2018; Zhu et al. 2018) was another motivation.

The AROME model has been configured over five tropical domains: the West Indies, French Guiana, the southwest Indian Ocean, New Caledonia, and French Polynesia. This set of configurations, which cover the most populated French overseas regions, is called the AROME overseas NWP system (denoted further as the AROME-OM system) and named, respectively, for each domain: AROME $E_{\text {Antilles }}, \mathrm{AROME}_{\text {Guiana }}, \mathrm{AROME}_{\text {Indian }}$, $\mathrm{AROME}_{\text {Caledonia }}$, and AROME $\mathrm{E}_{\text {Polynesia. }}$.

The AROME-OM system is designed to be as versatile as possible and is in particular not only focused on tropical cyclone forecasting. It is run every day, all yearlong, aiming to address all the forecaster needs from day 1 to day 3 including high-impact weather events, such as tropical cyclone landfalls and severe convection, but also local effects over steep islands and more 
generally the wide range of impact-based weather events such as aviation, energy, general public, and so on. Rain appears as a common factor across all these concerns and needs to be accurately forecasted whatever its intensity is.

The AROME-OM system is basically a downscaling, without any additional data assimilation, of the highresolution deterministic global model [Integrated Forecasting System (IFS)] from the European Centre for Medium-Range Weather Forecasts (ECMWF). This global model has a horizontal resolution of approximately $9 \mathrm{~km}$ and therefore uses a parameterization to simulate convection (Bechtold et al. 2014). It is known that, thanks to a better resolution for orography and a convection-permitting core, AROME can provide more realistic rain fields than its global forcing model (Clark et al. 2016; Seity et al. 2011). However, due to the initialization process and the following spinup, along with some usual caveats of mesocale models for rainfall forecasting such as the over (under) estimation of heavy (light) rainfall (Lean et al. 2008; Done et al. 2004), the rainfall forecast skills of AROME-OM system with respect to ECMWF IFS need to be characterized. On a practical basis, as rainfall forecasts of a convectionpermitting model can be quite different from those of a global model, a forecaster may not be confident enough to use the guidance of the former without a prior comprehensive assessment.

One of the difficulties for NWP systems in these tropical regions, compared to midlatitude regions like Europe for instance, is the scarcity of in situ observations: it makes both the initialization and the validation processes less reliable. While convection-permitting models that run operationally in the tropics become more and more common, their validation is not frequent in scientific literature, except for models dedicated for tropical cyclone forecasting, like HWRF (Bernardet et al. 2015). One of the most comprehensive studies to date is Woodhams et al. (2018), who characterized the added value of a convection-permitting model for forecasting extreme rainfall over East Africa. It notably shows that the mesoscale model outperforms the global one for rainfall forecasts over land, while over ocean the global model seems slightly better than the convection-permitting model.

This manuscript describes the results of an evaluation, focused on rainfall forecasts, of the AROME-OM system compared to its forcing model ECMWF IFS. This evaluation uses spatialized rainfall estimates at two time scales (daily and annual), from both satellite and ground-based instruments. It has been performed over a 10 -month period and across five tropical domains. The paper is organized as follows: section 2 describes the AROME-OM system itself and its main characteristics, section 3 is dedicated to the description of the references and methods used for the rainfall forecast verification, section 4 describes the rainfall verification for both references and for both time scales, and section 5 shows some case studies. Finally, section 6 summarizes the main findings and draws a few perspectives for the future evolution of this NWP system.

\section{Description of operational configurations}

A first version of the AROME-OM system was operationally implemented at Météo-France in February 2016. It was replaced by a more advanced version in December 2017 with major upgrades; the present paper evaluates this current version, during its preoperationnal stage that started from February 2017, on which an extensive validation had been performed to assess the performance of the new suite.

The AROME-OM system is mostly based on the AROME-France configuration run operationally centered over France. This configuration is described in Seity et al. (2011) and Brousseau et al. (2016). The major differences between the two are currently the horizontal resolution ( $2.5 \mathrm{vs} 1.3 \mathrm{~km}$, respectively) and the lack of a dedicated data assimilation scheme for the AROMEOM system: its initial conditions come mostly from ECMWF IFS. The global model from Météo-France, ARPEGE, was less suitable for this purpose due to its stretched grid that reaches its coarser resolution over the Pacific Ocean. More details on initial conditions are presented in section $2 \mathrm{c}$ along with some characteristics of the AROME-OM system in sections $2 \mathrm{a}$ and $2 \mathrm{~b}$; more details on general AROME model code components and canonical configurations are provided in the review paper by Termonia et al. (2018).

\section{a. Geographical domains and model grid}

Figure 1 shows the five geographical domains considered; each of them uses a $2.5-\mathrm{km}$ regular grid on a Lambert projection. As summarized in Table 1, their sizes vary from $473 \times 357$ grid points $\left(\mathrm{AROME}_{\text {Guiana }}\right)$ to $1573 \times 873$ grid points $\left(\mathrm{AROME}_{\text {Indian }}\right)$. The majority of their grid points are over ocean, with a fraction of land grid points ranging between $31.5 \%$ (AROME $_{\text {Guiana }}$ ) and $0.1 \%$ (AROME $E_{\text {Polynesia }}$ ). Regarding the orography in each of the domains, the fraction of grid points with an elevation greater than $500 \mathrm{~m}$ is negligible for the AROME $_{\text {Guiana }}$ domain (1\%), but reaches $46.9 \%$ for the AROME $_{\text {Indian }}$ domain.

\section{b. Model dynamics, physics, and surface}

The five configurations of the AROME-OM system share a same tuning of AROME dynamics and physics, 


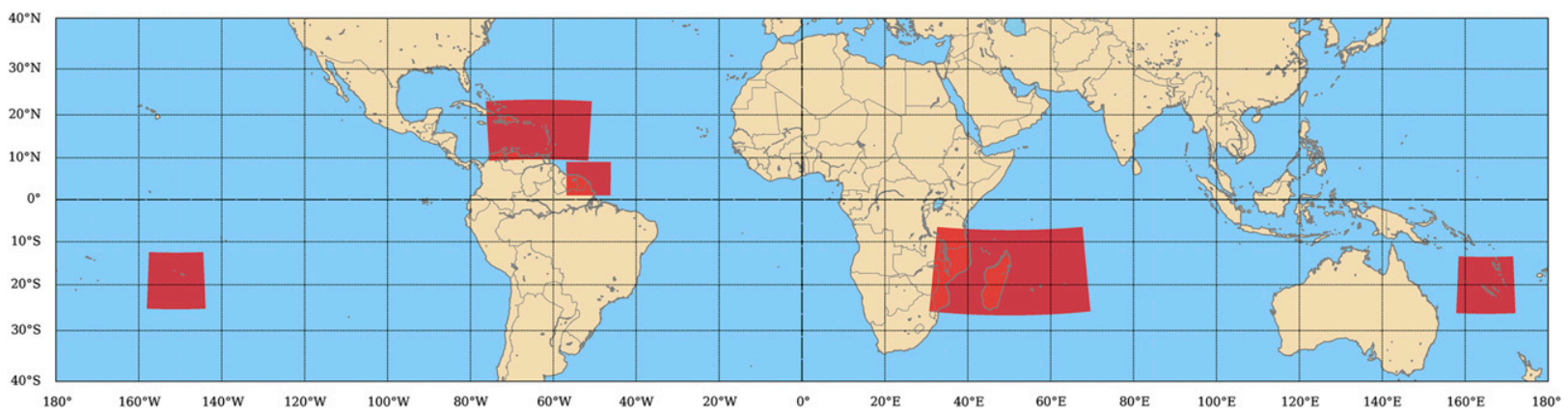

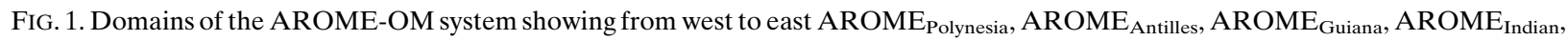
and AROME $E_{\text {Caledonia. }}$

described hereafter. The vertical discretization uses 90 vertical levels, from $5 \mathrm{~m}$ up to approximately $34 \mathrm{~km}$, with mass-based hybrid pressure terrain-following coordinate $\eta$. These configurations use a nonhydrostatic dynamical core and are run with a 60-s time step with two iterations of a light predictor-corrector scheme. Lateral boundary coupling uses a Davies relaxation scheme, with a 1-h frequency refresh from the forcing model, the ECMWF IFS introduced before. The semi-Lagrangian horizontal diffusion (Ván̆a et al. 2008) of hydrometeors has been slightly decreased compared to the AROMEFrance configuration, to take into account the differences of horizontal resolution ( $2.5 \mathrm{vs} 1.3 \mathrm{~km}$ ) and of time step (60 vs $50 \mathrm{~s})$.

Compared to the AROME-France configuration, the AROME-OM system has no specific tuning of its physics parameterizations. With regards to convection, the AROME-OM system uses a mass flux shallow convection scheme (Pergaud et al. 2009), that is nonprecipitating; no deep convection scheme is activated. AROME also uses a turbulence scheme based on a prognostic equation of turbulent kinetic energy (Cuxart et al. 2000), and a onemoment microphysics prognostic scheme (Pinty and Jabouille 1998). The radiation scheme is a simplified version of the ECMWF radiation parameterization (Mlawer et al. 1997; Fouquart and Bonnel 1980; Morcrette 1991).

With regards to the surface, the AROME-OM system uses the same surface modeling platform as AROMEFrance, called SURFEX (Masson et al. 2013), with one addition: the activation of the 1D ocean model with inline coupling. This feature allows better forecasting of the intensity of tropical cyclones, thanks to the ability to represent the cooling of the sea surface temperature in the vicinity of tropical cyclones (Davis et al. 2008; Samson et al. 2009).

\section{c. Initialization and operational runs}

As said previously, the AROME-OM system does not have its own data assimilation scheme. For each run, initial conditions are gathered from three different global models: ECMWF IFS, Météo-France ARPEGE, and Mercator-Ocean PSY4. They are used to initialize, respectively, the atmosphere, the land, and the ocean components of AROME.

More precisely, regarding the atmosphere, the variables of surface pressure, temperature, wind components and humidity are initialized by IFS fields, interpolated from a $16-\mathrm{km}$ grid with quadratic troncature. To mitigate the initial spinup phase, an incremental analysis update algorithm (Bloom et al. 1996) is used to add large-scale information from the most recent IFS analysis in a 6-h AROME forecast that starts $6 \mathrm{~h}$ before the required initial conditions. Doing so makes the initial AROME fields to be representative of the actual model resolution and the convective features to be represented, while benefiting from the latest large-scale analysis from IFS.

For continental surfaces, AROME and IFS use different parameterizations, named, respectively, Interactions between Soil, Biosphere, and Atmosphere (ISBA; Noilhan and Planton 1989) and Tiled ECMWF Scheme for Surface Exchanges over Land (TESSEL; van den Hurk et al. 2000). They differ in many aspects, from land-use databases to fundamental concepts, like the discretization of the soil or the formulation of the exchanges between the levels. Therefore, computing ISBA variables from TESSEL ones is not straightforward and requires

TABLE 1. For each AROME-OM domain, dimensions of the horizontal grid [zonal $(x) \times$ meridional $(y)$ sizes], fraction of grid points over land with respect to the full domain, and fraction of grid points with an elevation higher than $500 \mathrm{~m}$ with respect to the number of grid points over land.

\begin{tabular}{lrcc}
\hline \hline $\begin{array}{l}\text { AROME } \\
\text { domain }\end{array}$ & $x \times y$ & $\begin{array}{c}\text { Fraction of grid } \\
\text { points over land }\end{array}$ & $\begin{array}{c}\text { Fraction of land grid } \\
\text { points }>500 \mathrm{~m}\end{array}$ \\
\hline Antilles & $1053 \times 613$ & $8.5 \%$ & $24.9 \%$ \\
Caledonia & $573 \times 573$ & $1.5 \%$ & $12.4 \%$ \\
Guiana & $473 \times 357$ & $31.5 \%$ & $1.0 \%$ \\
Indian & $1573 \times 873$ & $23.4 \%$ & $46.9 \%$ \\
Polynesia & $573 \times 573$ & $0.1 \%$ & $22.8 \%$ \\
\hline
\end{tabular}


(i)
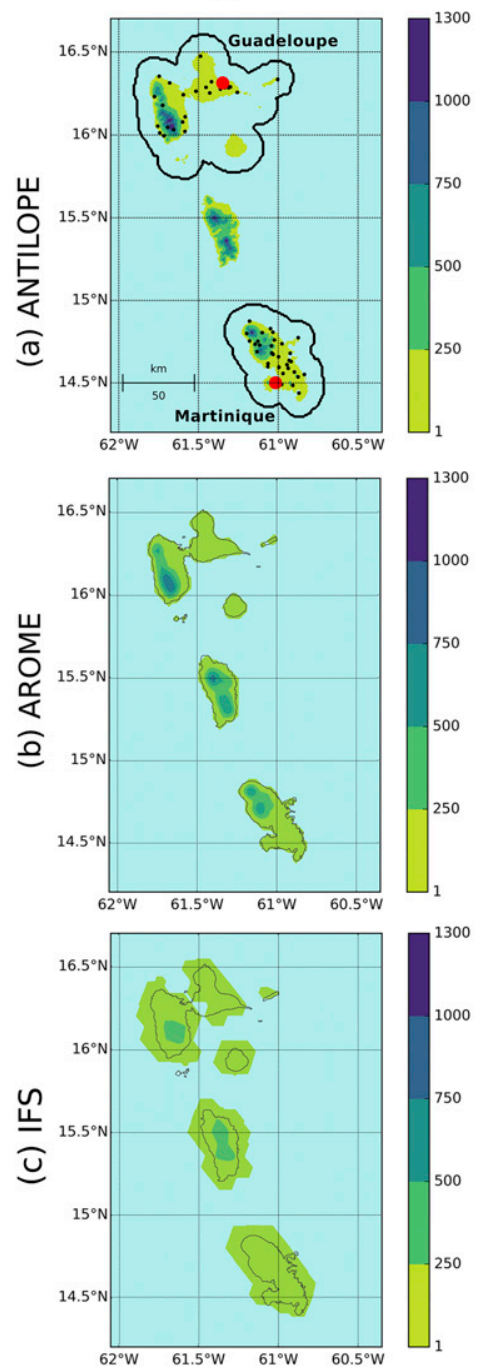

(ii)
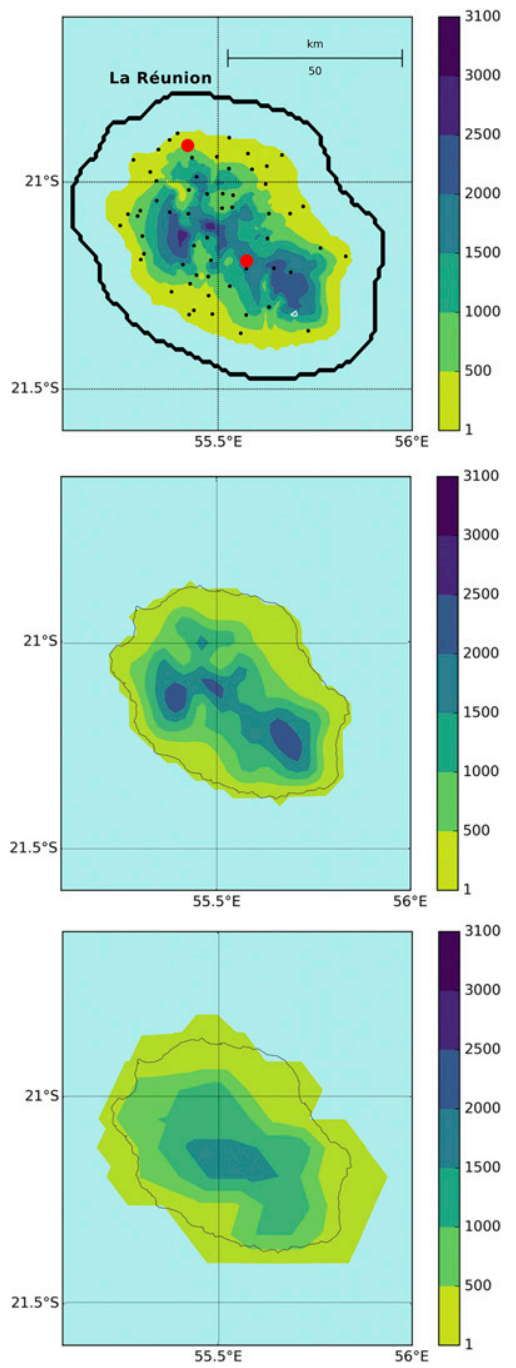

(iii)
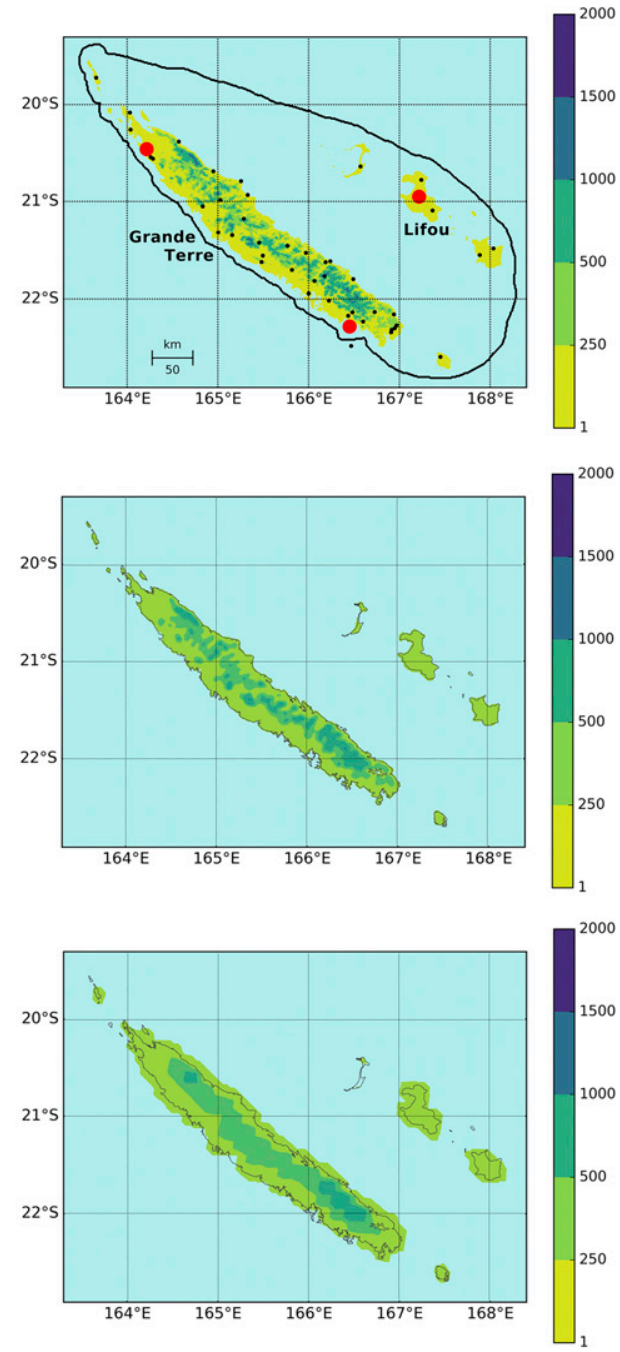

FIG. 2. (a) ANTILOPE domains (black contours) with the rain gauges (black dots) and radars (red points) used for rainfall estimation; shaded colors represent elevation from the GMTED2010 database, and names of the main islands are indicated in black. Shown are the (i) ANTILOPE $_{\text {Antilles, }}$, (ii) ANTILOPE Indian, and (iii) ANTILOPE $_{\text {Caledonia }}$ domains. (b) The actual orography used by AROME model, and (c) the actual orography used by IFS model.

several strong assumptions. After severals tests (not shown), it has been shown that using ARPEGE surface fields, which also use ISBA parameterization, was more beneficial to AROME than using IFS surface fields. Consequently, an interpolation from the ARPEGE grid is performed toward each AROME-OM domain for all the surface fields at the beginning of each run.

Concerning the ocean, the $1 \mathrm{D}$ ocean model variables (current components, salinity, temperature) are initialized by Mercator-Ocean global model PSY4, which has a horizontal resolution of $1 / 12^{\circ}$ (Lellouche et al. 2018).

These configurations are run four times a day, at 0000, 0600,1200 , and $1800 \mathrm{UTC}$, up to a lead time of $42 \mathrm{~h}$ on a daily basis, and up to $78 \mathrm{~h}$ on demand (mainly during tropical cyclone warnings). Outputs on regular latitudelongitude grids are postprocessed each hour. These forecasts are run on the Météo-France high-performance computer in Toulouse, France, and then disseminated to overseas regions and are freely available online as well. ${ }^{1}$

\section{Data and method for rainfall forecast verification}

For the intercomparison presented in this paper, daily AROME forecasts have been performed at 0000 UTC

\footnotetext{
${ }^{1}$ https://donneespubliques.meteofrance.fr/?fond = produit\&id produit $=241 \&$ id_rubrique $=51$ (fr).
} 
TABLE 2. List of the precipitation products used as reference in the intercomparison of rainfall forecasts.

\begin{tabular}{llrrr}
\hline \multicolumn{1}{c|}{ Product name } & \multicolumn{1}{c}{ Observational source } & $\begin{array}{c}\text { Native } \\
\text { resolution }\end{array}$ & $\begin{array}{c}\text { Surface } \\
\text { covered }\left(\mathrm{km}^{2}\right)\end{array}$ & $\begin{array}{c}\text { Fraction of the AROME } \\
\text { domain(s) covered by } \\
\text { the product }\end{array}$ \\
\hline ANTILOPE $_{\text {Antilles }}$ & Rain gauges (62) and ground radar (2) & $1 \mathrm{~km} / 1 \mathrm{~h}$ & 10027 & $0.25 \%$ \\
ANTILOPE $_{\text {Indian }}$ & Rain gauges (60) and ground radar (2) & $1 \mathrm{~km} / 1 \mathrm{~h}$ & 4113 & $0.05 \%$ \\
ANTILOPE & Raledonia \\
3B42RT-V7 & Rain gauges (45) and ground radar (3) & $1 \mathrm{~km} / 1 \mathrm{~h}$ & 81334 & $3.95 \%$ \\
& $\begin{array}{l}\text { Microwave observations from low Earth orbiting } \\
\text { satellites and thermal infrared observations from } \\
\text { GSMAP }\end{array}$ & $0.25 \% 3 \mathrm{~h}$ & - & $100 \%$ \\
\hline
\end{tabular}

up to a +24-h range for the five AROME-OM domains. These forecasts have been produced with version cy $42 \mathrm{t} 1$ of the AROME code over a 10-month period starting on 1 February 2017 and ending on 5 December 2017. This period corresponds to a preoperational phase, during which this suite was exhaustively validated before being put into operation. The produced data have been stored at their native horizontal resolution of $2.5 \mathrm{~km}$. The IFS 24-h rainfall forecasts of 0000 UTC have also been extracted from the ECMWF archive on the native cubicoctahedral grid. The rainfall forecasts from both systems have been averaged at several scales depending on the reference verification dataset used as explained below.

\section{a. Reference datasets and space scales for intercomparison}

For three of the five AROME domains, a rainfall product, named ANTILOPE, is available and combines observations from rain gauges and ground radar data (Laurantin 2008; Champeaux et al. 2011), to provide a spatialized rainfall field centered on radars. The areas for which this ground-based rainfall product is available are shown in Fig. 2, along with the locations of the rain gauges and the ground-based radars used, the elevation, and the name of the main islands. As shown in Table 2, the ANTILOPE products are provided at a native $1-\mathrm{km} / 1-\mathrm{h}$ resolution. The ANTILOPE $\mathrm{C}_{\text {Caledonia }}$ product covers the largest area of the three products, with virtually no coverage overlap between its three radars, and it includes a rather large portion of oceanic surface for which no rain gauge calibration is performed. The number of rain gauges over land is also the smallest of the three domains with 45 instruments, compared to 62 and 60, respectively, for the ANTILOPE Antilles $_{\text {and }}$ ANTILOPE $E_{\text {Indian }}$ products. A comprehensive validation of these products has been performed (Météo-France internal reports): for each domain the ANTILOPE product and the raw radar estimates have been compared to independent rain gauge data over several months, with several metrics and for different classes of rainfall intensity. All ANTILOPE products have lower root-mean-square errors and better equitable threat scores than the raw radar estimate, for all rainfall intensities and for the three domains. According to these criteria, the best quality product is ANTILOPE $_{\text {Indian }}$ and the lowest one is ANTILOPE Caledonia; the three products have nonetheless less skill than their inland France counterpart.

For the domains ANTILOPE Antilles, $_{\text {, ANTILOPE }}$ Indian,

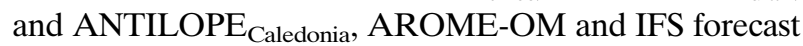
datasets have been interpolated onto the $1-\mathrm{km}$ grid of ANTILOPE. While being at a higher resolution than the forecasts of the two models, in particular for the IFS forecasts at the coarsest resolution, this comparison at the kilometric scale characterizes the strength and weaknesses of forecasts with respect to the orography and to the landocean contrasts, which are important aspects for forecasters.

Although of high interest for French forecasters, the areas covered by these ANTILOPE datasets are rather small with respect to the full domain sizes (see Table 2): $0.25 \%$ for the $\mathrm{AROME}_{\text {Antilles }}$ forecasts, $3.95 \%$ for the AROME $E_{\text {Caledonia }}$ forecasts, and $0.05 \%$ for the AROME $E_{\text {Indian }}$ forecasts. Therefore, a complementary kind of rainfall estimate was also used as reference and consists of satellite-based precipitation products. Indeed, various intercomparisons studies, several of which are led by the International Precipitation Working Group ${ }^{2}$ (Levizzani et al. 2018), have shown that these products can provide highly relevant precipitation estimates. In particular, it was shown to be the case in the tropics (e.g., Gosset et al. 2018), where the emission and scattering signals observed from space by various microwave sensors can be strongly correlated to surface rainfall resulting from deep convection. Among the variety of available satellite-based products, two intensively validated products have been selected for this study: (i) the TRMM-3B42RT-V7 product (Huffman et al. 2007, denoted further as 3B42RT-V7) and (ii) the GSMAP product (Kubota et al. 2007). These products

\footnotetext{
${ }^{2}$ http://www.isac.cnr.it/ ipwg/.
} 
both belong to the category of merged microwave/infrared datasets; they use almost the same satellite data as input and no rain gauge data to provide an independent set compared to the ANTILOPE product. Nonetheless, the algorithms to retrieve instantaneous precipitation from microwave observations as well as the algorithms to merge these estimates with infrared observations are rather different. Therefore, verifying the model forecasts with these two products is interesting as it provides widely independent references.

For these comparisons, the IFS, AROME, 3B42RT-V7, and GSMAP datasets have been averaged onto the same common horizontal grid of $0.5^{\circ}$. This resolution is a quite coarse one for assessing the performance of a mesoscale model like AROME, but (i) it is the lowest common multiple of 3B42RT-V7 and GSMAP resolutions, and (ii) it does provide complementary information with respect to the ANTILOPE comparisons.

\section{b. Time scales and metrics}

In this study, rainfall forecasts skills have been assessed at two different time scales: a daily one and a longer one called the annual time scale. The two selected scales both present a scientific interest to estimate the added value of the AROME-OM system compared to its forcing model, ECMWF IFS, giving, respectively, day to day and climatological assessments. These two scales are also of primary importance for the end-users: the daily scale is used every day by the forecasters, while the annual one is able to highlight the most important biases of the models that forecasters must be aware of.

No subdaily skill comparison is performed within this paper, because (i) the uncertainty of the references at such time scales requires an even longer period of study and (ii) the diurnal cycle over these oceanic regions is weaker than over continent. This subdaily assessment will be addressed in a future paper.

For what is called the annual scale, all rainfall products have been accumulated over the 10-month period. Then several basic metrics are used: bias, coefficient of determination (Murphy 1995), corresponding to the square of the correlation coefficient, and rainfall maps to show the different rainfall geographical patterns. Section $4 \mathrm{a}$ reports the results of the intercomparison at the annual time scale, both with respect to the ANTILOPE product [section $4 \mathrm{a}(1)$ ] and with respect to the satellite products [section $4 \mathrm{a}(2)]$.

For the daily scale, all rainfall products have been accumulated over $24 \mathrm{~h}$ and are intercompared. Two different metrics are used for assessing the daily variability: occurrence histograms as well as a skill score known as the fractions skill score (noted further FSS, Roberts and Lean 2008). This FSS measures the degree of agreement

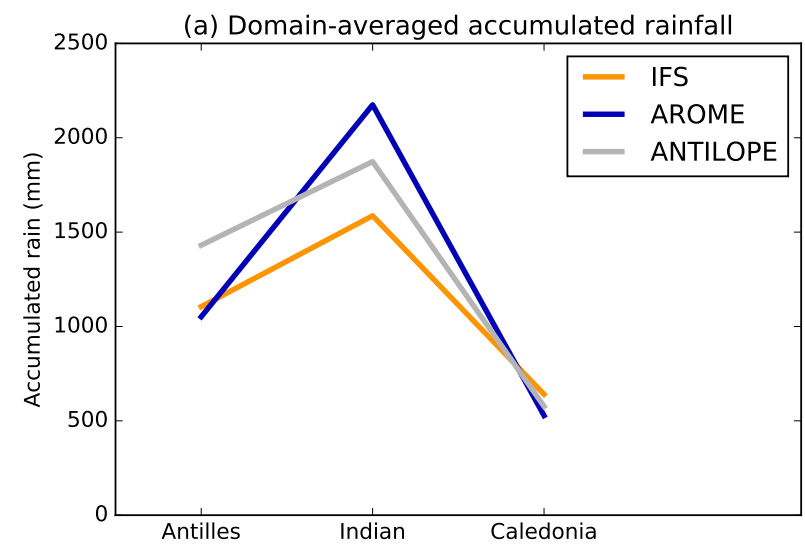

(b) Bias of domain-averaged accumulated rainfall
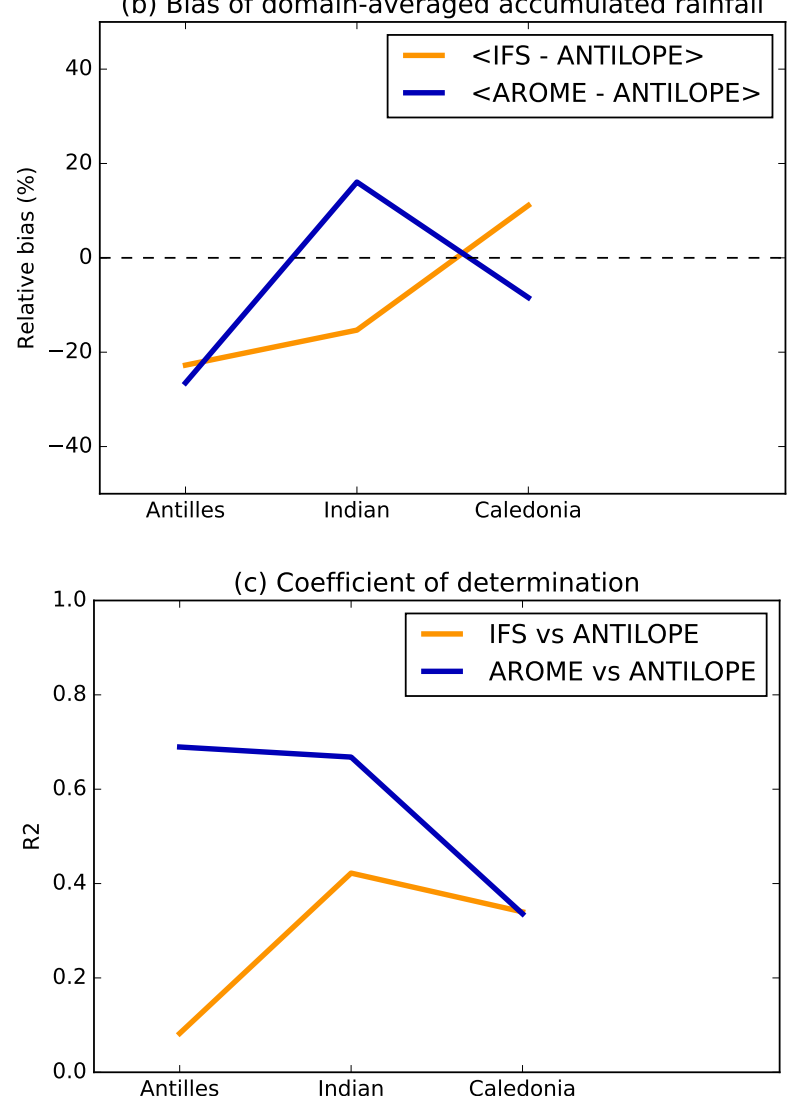

FIG. 3. Domain-averaged rainfall accumulation for the 10-month period for the three ANTILOPE domains and for the models AROME and IFS (a) total amount, (b) bias, and (c) coefficient of determination compared to the ANTILOPE product.

between the forecast and the reference above a certain rainfall threshold and within a given neighborhood; this score belongs to the family of fuzzy verification scores (Ebert 2008). Section 4b reports the results of the intercomparison at the daily time scale, both with respect to the ANTILOPE product [section $4 \mathrm{~b}(1)$ ] and with respect to the satellite products [section $4 \mathrm{~b}(2)]$. 
(i)
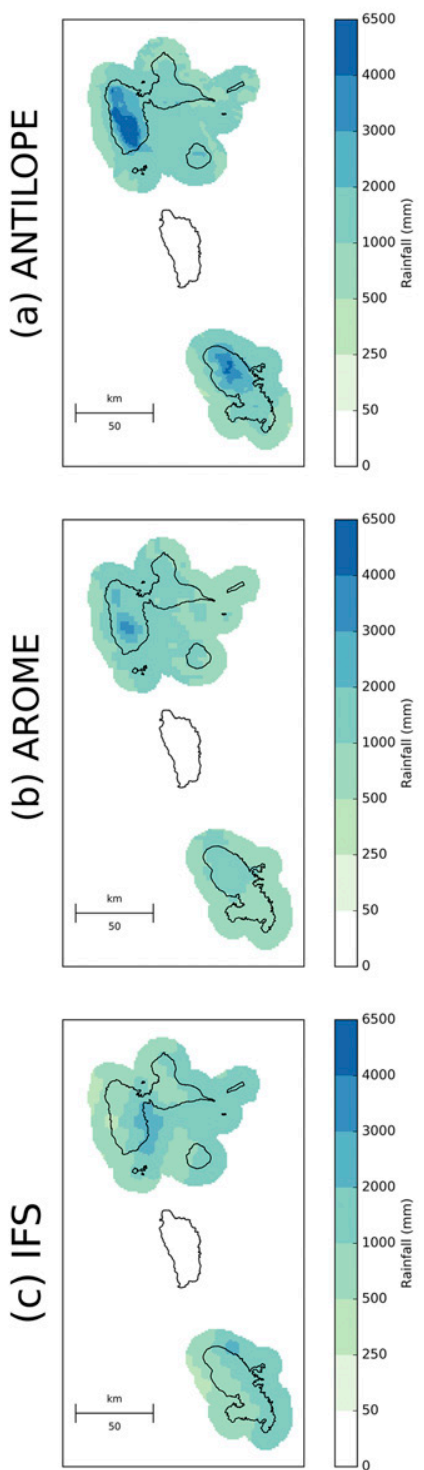

(ii)
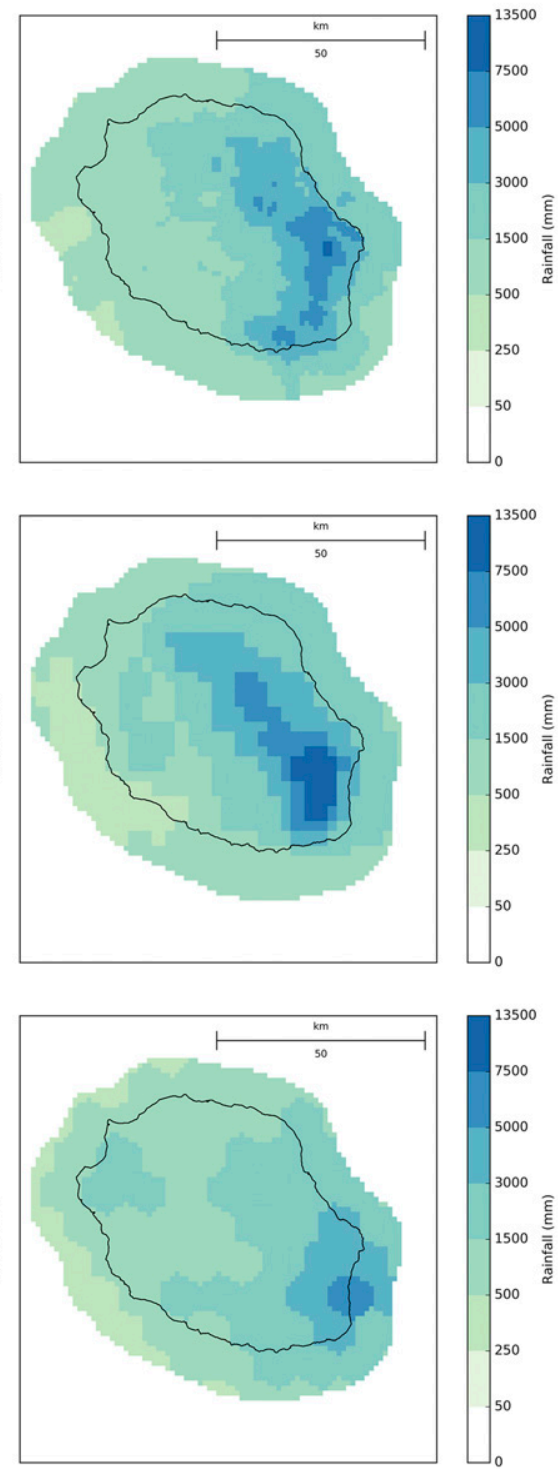

(iii)
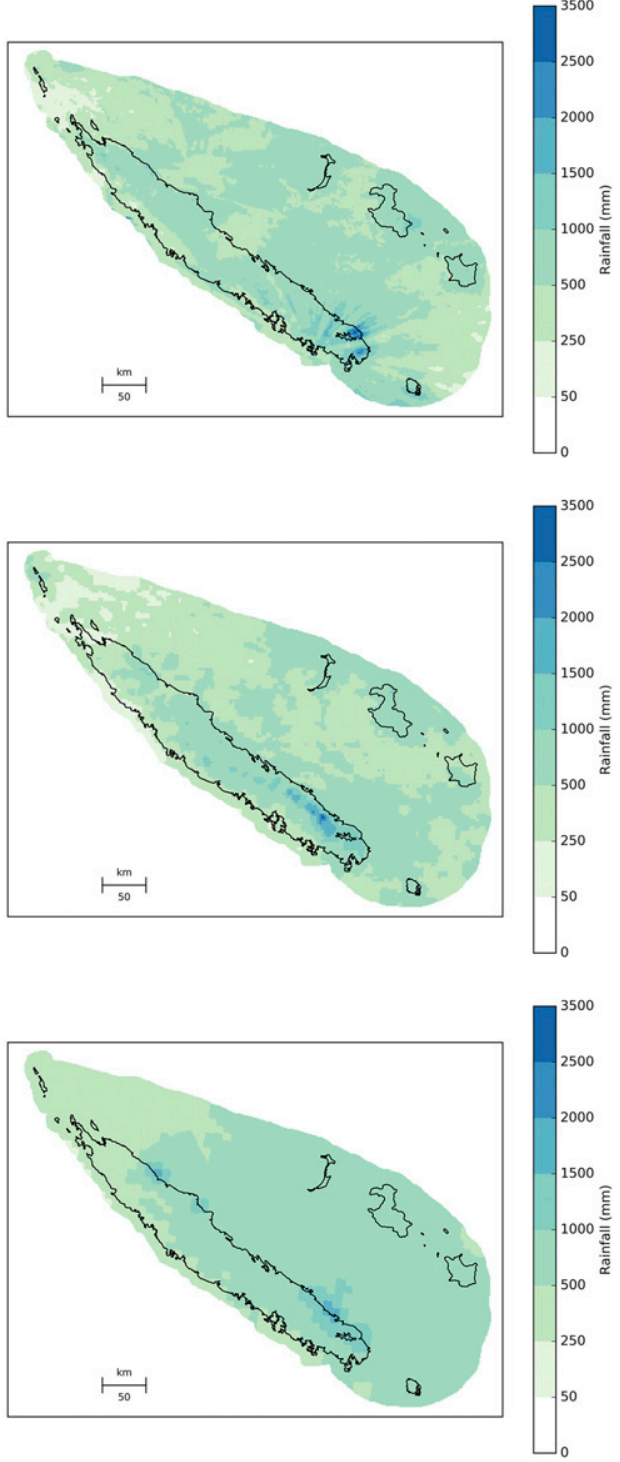

FIG. 4. Rainfall accumulation maps for the 10-month period and for the three ANTILOPE domains: (i) Antilles, (ii) Indian, and (iii) Caledonia. For each domain, use of a common 1-km-resolution grid and plot of three datasets: (a) ANTILOPE reference, (b) AROME, and (c) IFS.

\section{Results of the intercomparison}

\section{a. Intercomparison at the annual scale}

\section{1) ANNUAL SCALE With RESPECT TO COMBINED RADAR/RAIN GAUGE PRODUCTS}

Figure 3a shows the domain-averaged accumulated rainfall of ANTILOPE, AROME, and IFS for the 10-month period over the three ANTILOPE domains, and Fig. $3 \mathrm{~b}$ shows their biases compared to the ANTILOPE product. While domain-averaged accumulations are similar for both models over the ANTILOPE Antilles $_{\text {and }}$
ANTILOPE $_{\text {Caledonia }}$ domains, this amount of rainfall is quite different over the ANTILOPE Indian $_{\text {domain with }}$ a total rain accumulation of AROME greater than the IFS one by $500 \mathrm{~mm}$. When compared to the ANTILOPE product, both models underestimate rainfall accumulation by roughly $20 \%$ over the ANTILOPE Antilles $_{\text {do- }}$ main; for the other two domains, biases range from $15 \%$ to $20 \%$ and are of opposite signs for IFS and AROME. Figure $3 \mathrm{c}$ shows the coefficient of determination (denoted $R^{2}$ ) between both models and ANTILOPE products; it is a simple metric that can be used to determine which model explains a larger fraction of variance of 
TABLE 3. Maxima of rainfall accumulation ( $\mathrm{mm}$ ) over the full period on ANTILOPE domains for models and reference.

\begin{tabular}{cccc}
\hline \hline ANTILOPE domain & ANTILOPE & AROME & IFS \\
\hline Antilles & 6472 & 3554 & 2954 \\
Indian & 7989 & 12213 & 5101 \\
Caledonia & 3265 & 2585 & 1771 \\
\hline
\end{tabular}

the ANTILOPE product than the other. It appears that AROME outperforms IFS on ANTILOPE Antilles $_{\text {and }}$ ANTILOPE Indian domains, with $R^{2}$ above 0.6, while both models have the same average $R^{2}$ of 0.4 on ANTILOPE $E_{\text {Caledonia }}$ domain. These domain-averaged metrics can be further explained by the geographical variability of rainfall accumulations, shown on Fig. 4 for the three ANTILOPE domains. The maxima of rainfall of each map of this latter figure are reported in Table 3. Figure 2 gives for the three ANTILOPE domains the orography actually used by AROME and IFS (Figs. 2b and $2 \mathrm{c}$, respectively), with the same colorbar as the real orography (Fig. 2a).

- Over the ANTILOPE $E_{\text {Antilles }}$ domain, the maximum of rainfall estimated by ANTILOPE is approximately twice as big as the ones from AROME and IFS (see Table 3). Nevertheless, AROME rainfall patterns are more realistic than IFS ones: the maxima of AROME rainfall are located on mountainous areas of Guadeloupe and Martinique [Fig. 4b(i)], while IFS ones are on the shore [Fig. 4c(i)], upstream of the relief. While the poorer representation of the relief by IFS than by AROME [Figs. 2c(i),b(i)] could explain why the IFS rainfall maximums are smaller than AROME ones, it does not explain why they occur over the sea rather than on the mountain slopes.

- Over the ANTILOPE Indian $_{\text {domain, like for the pre- }}$ vious one, AROME rainfall patterns are much closer to ANTILOPE rainfall patterns than IFS ones; the highest amounts of AROME rainfall are located on windward mountainous regions [Fig. 4b(ii)], while IFS ones are more upstream [Fig. 4c(ii)]. As reported in Table 3, the AROME maximum total amount is $12213 \mathrm{~mm}$ of rain, which is larger than the ANTILOPE one by $61 \%$ as well as larger than the IFS one by $138 \%$. Like for the ANTILOPE Antilles $_{\text {domain, IFS uses a less }}$ realistic topography than AROME [Figs. 2c(ii),b(ii)]. This difference in topography could explain the difference of magnitude between the rainfall maximums of IFS and AROME, but it does not explain their difference of localization, the IFS maximum being on the shore rather than on the slope.

- Over the ANTILOPE Caledonia $_{\text {domain, the maximum }}$ of total rainfall estimated by ANTILOPE is better estimated by AROME than by IFS. Some geographical
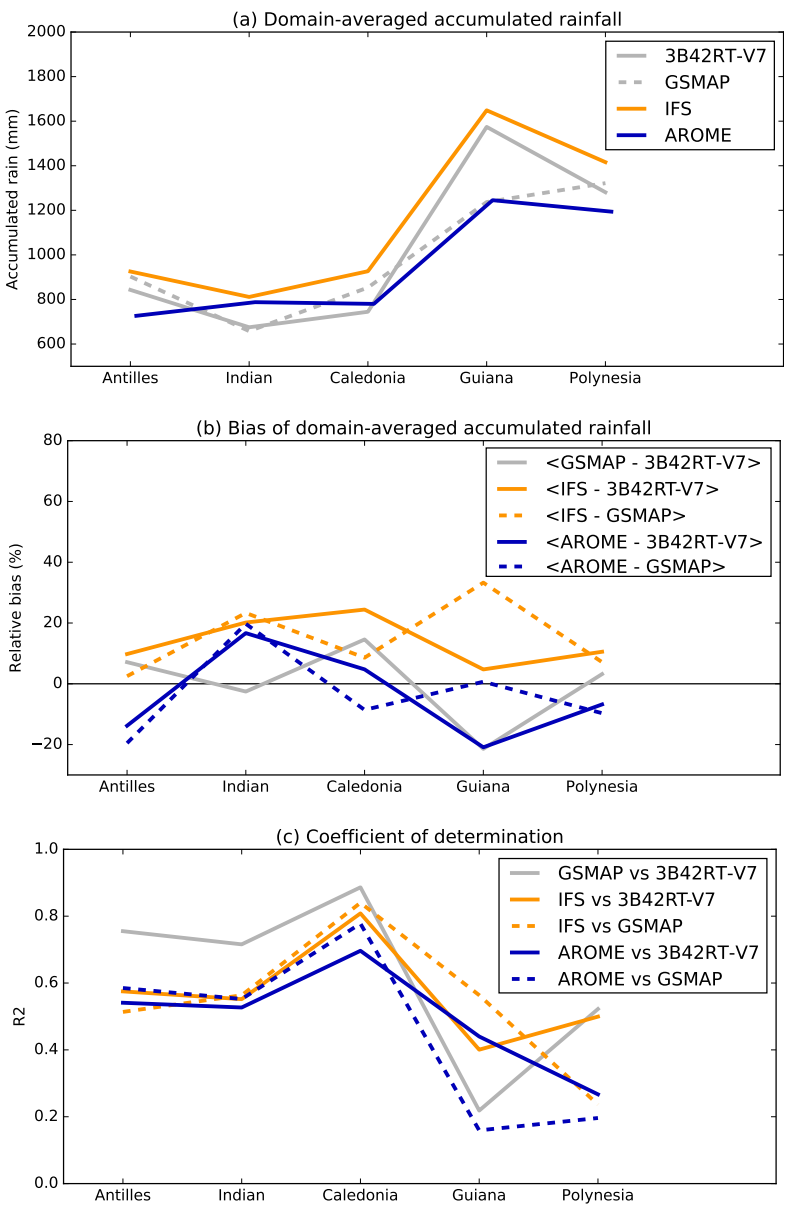

FIG. 5. Domain-averaged rainfall accumulation for the 10-month period, for the five AROME domains and for the models AROME and IFS (a) total amount, (b) bias, and (c) coefficient of determination compared to both satellite products 3B42RT-V7 and GSMAP.

patterns of rainfall in particular places are better depicted with AROME: for instance, IFS highest accumulations are only located over the southern and the eastern parts of the New Caledonia main island (Grande Terre) [Fig. 4c(iii)], while AROME is able to realistically locate high amounts of rainfall inland [Fig. 4b(iii)]. When ANTILOPE products have been introduced in section $3 \mathrm{a}$, it has been said that the ANTILOPE Caledonia $_{\text {product should be used with }}$ more caution than for the other two domains, as one can note on Fig. 4a(iii) where visible portions of the radar beam appear on rainfall estimates on the southern part of Grande Terre.

At this local scale, and across the three domains, it is clear that AROME is able to provide much more realistic patterns of rainfall accumulation on the annual average. Indeed, its largest accumulations occur over 


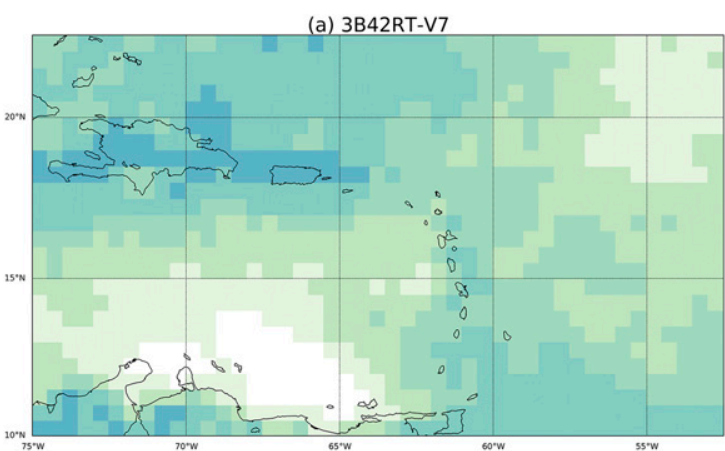

(b) GSMAP
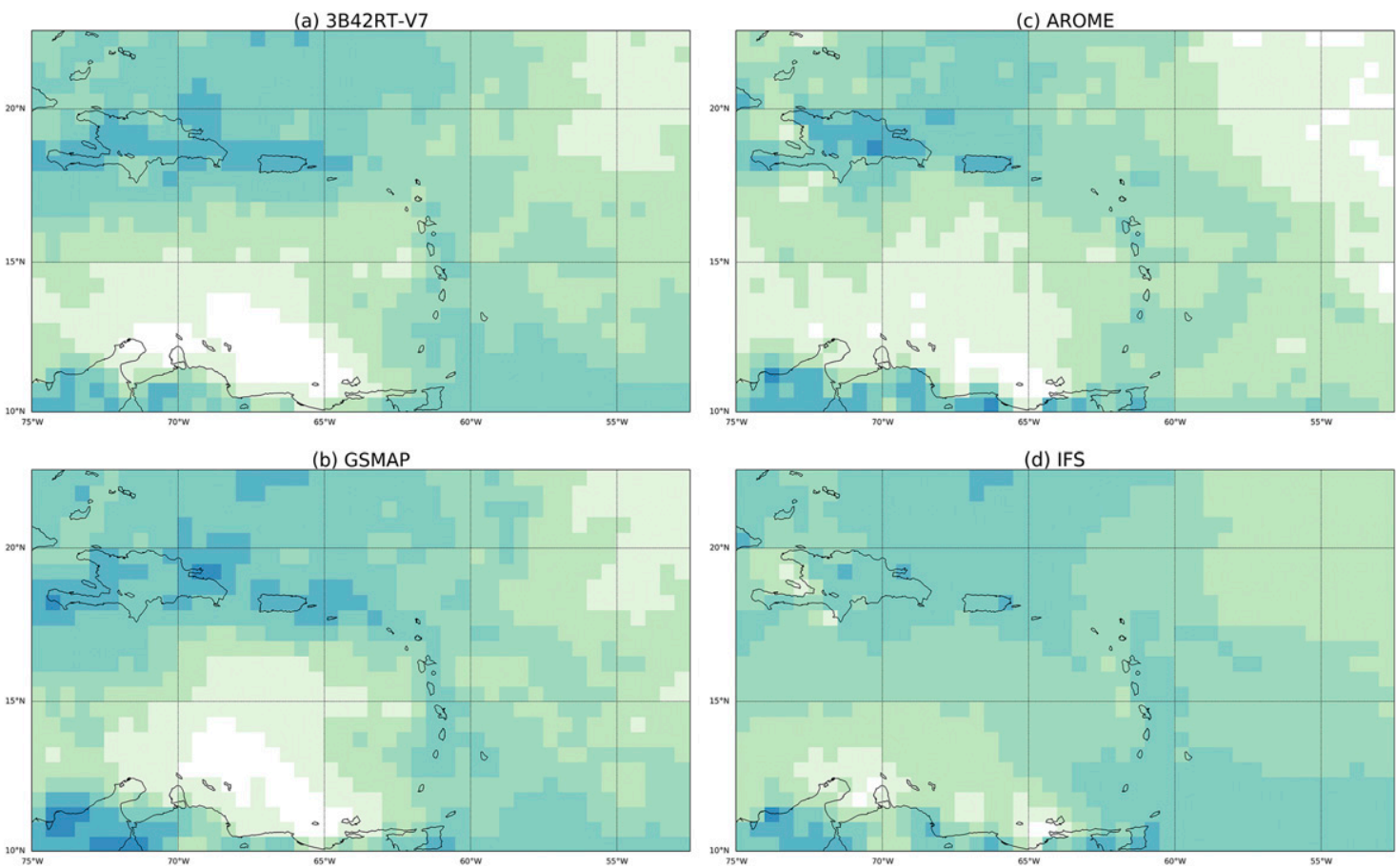

(d) IFS
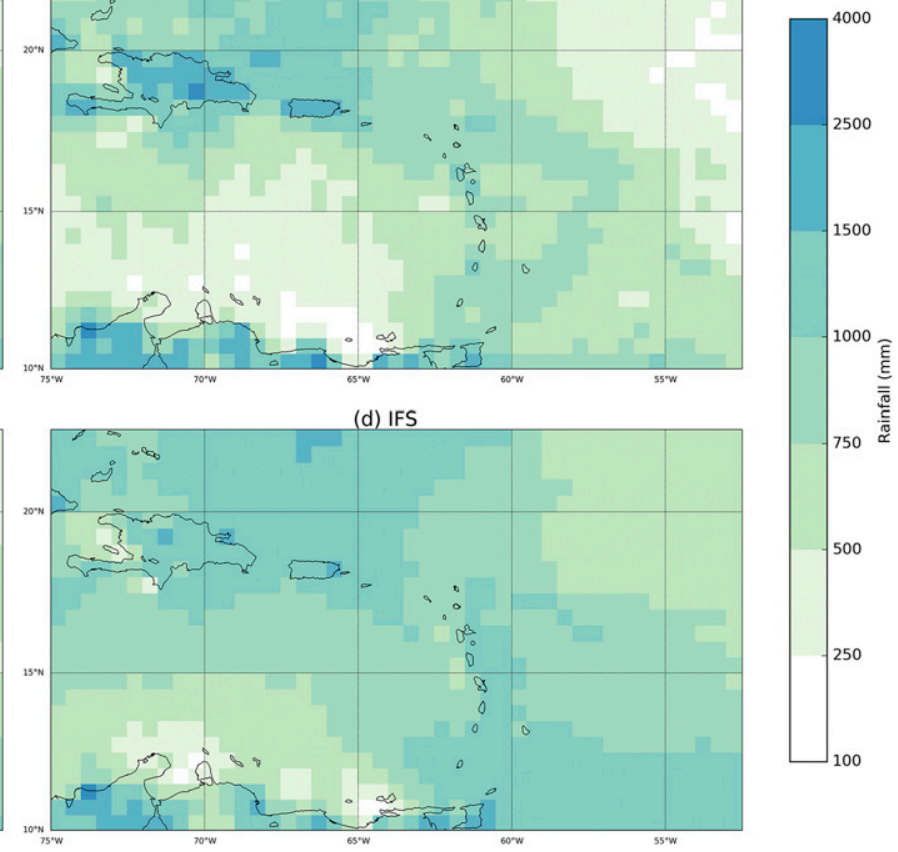

FIG. 6. Rainfall accumulation maps for the 10-month period for the AROME Antilles domain on a common $0.5^{\circ}$-resolution grid; shown are data from satellite products (a) 3B42RT-V7 and (b) GSMAP and from models (c) AROME and (d) IFS.

summits and on windward coasts, while IFS tends to localize its largest accumulations on the shore. The difference between the actual orographies used by these two models can explain the difference in magnitude of the rainfall, but not the difference in localization: even with very underestimated orography, IFS tends to localize its maximum of rainfall on the shore and not on the slopes of the mountains. These more realistic patterns simulated by AROME than IFS explain why the coefficients of determination are so different between the two models over the ANTILOPE Antilles $_{\text {and }}$ ANTILOPE Indian $_{\text {domains, }}$ which are focused on small islands with steep orography. The IFS largest accumulations are always smaller than the ANTILOPE ones. The bias between ANTILOPE and AROME varies from one domain to another concerning the highest accumulations: a large underestimation over both Antilles islands and large overestimation over La Réunion island. The latter may be explained by the very steep orography of this island, showing then a bias of AROME to overintensify orographic convective precipitation over high mountains as noticed by forecasters for AROME France.

\section{2) ANNUAL SCALE With RESPECT TO SATELLITE RAINFALL PRODUCTS}

Figure 5a shows the domain-averaged accumulated rainfall of AROME and IFS during the 10-month period over the five AROME domains, and Fig. 5b its bias compared to the two satellite rainfall products. Except over the AROME Indian $_{\text {domain, IFS rain accu- }}$ mulations are always higher than AROME ones by 200-400 mm. The two references 3B42RT-V7 and GSMAP also do not provide the exact same accumulations over the 10-month period: Fig. $5 \mathrm{~b}$ indicates that for the three domains of $\mathrm{AROME}_{\text {Antilles }}$, AROME $\mathrm{Andian}_{\text {, }}$ and AROME $E_{\text {Polynesia }}$, 3B42RT-V7 and GSMAP only differ by less than $5 \%$ but differ much more for the $\mathrm{AROME}_{\text {Caledonia }}$ and $\mathrm{AROME}_{\text {Guiana }}$ domains (almost $20 \%$ of difference for the latter). The $\mathrm{AROME}_{\mathrm{Guiana}}$ domain is characterized by the largest fraction of land $(31.5 \%$, see Table 1$)$ for which the estimation of precipitation from space is more difficult than over ocean because of land surface emissivity. It is therefore not surprising that the two products 3B42RT-V7 and GSMAP differ the most for this particular area.

With respect to the biases reported in Fig. 5b, IFS has a positive one compared to both products and over the five AROME domains. In comparison, the sign of the AROME bias is more domain dependant and can be further explained with the rainfall maps shown in Figs. 6-10:

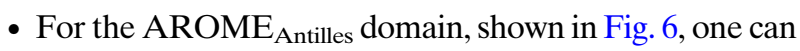
see large-scale rainfall patterns as estimated by the two satellite products with two drier areas in the northeastern 


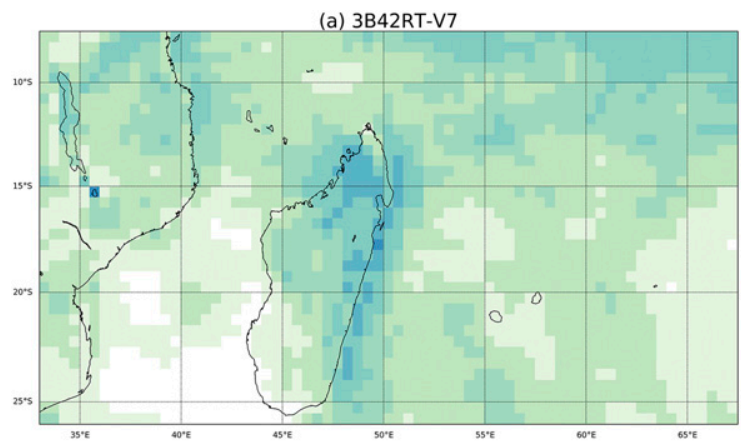

(b) GSMAP
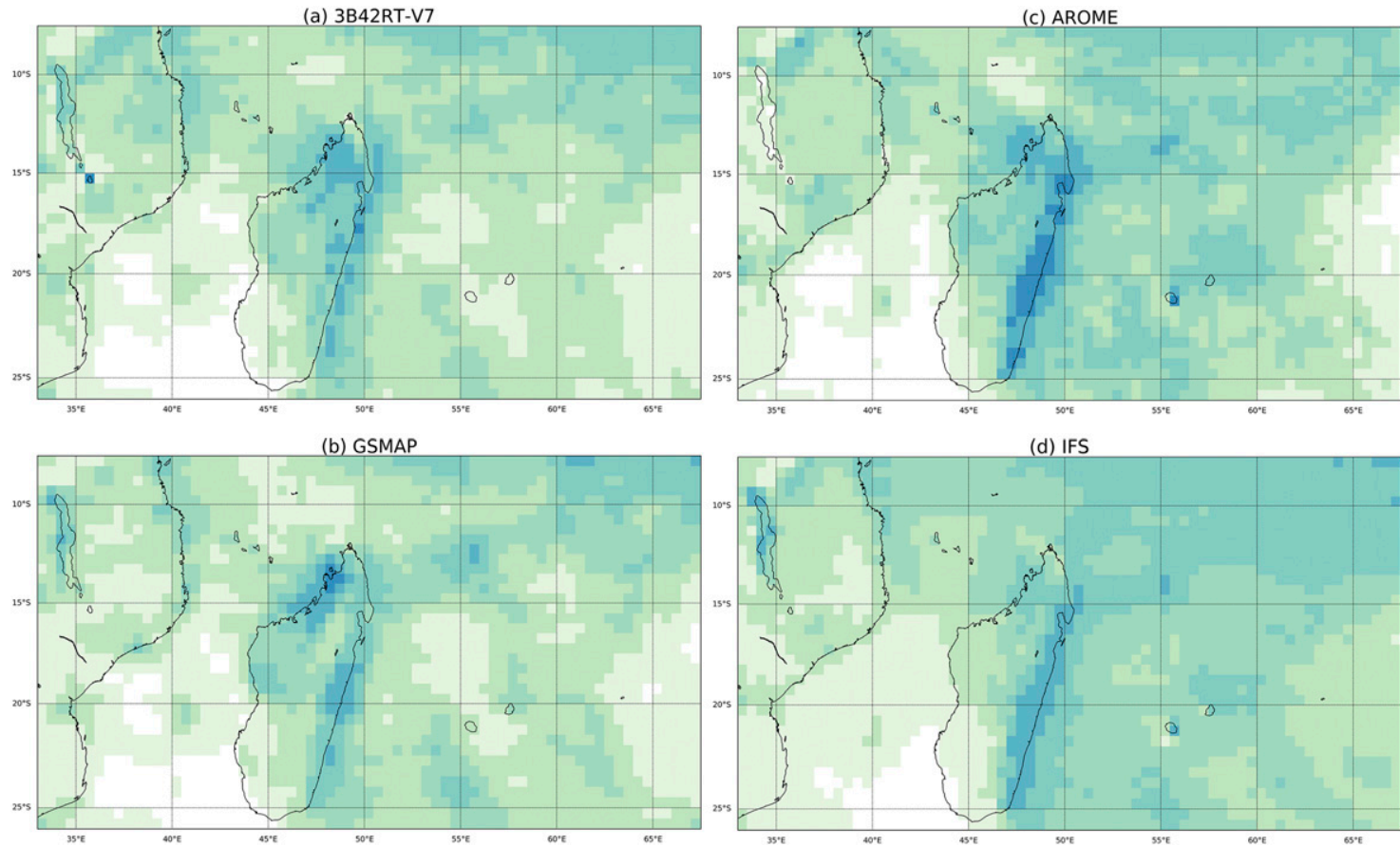

(d) IFS

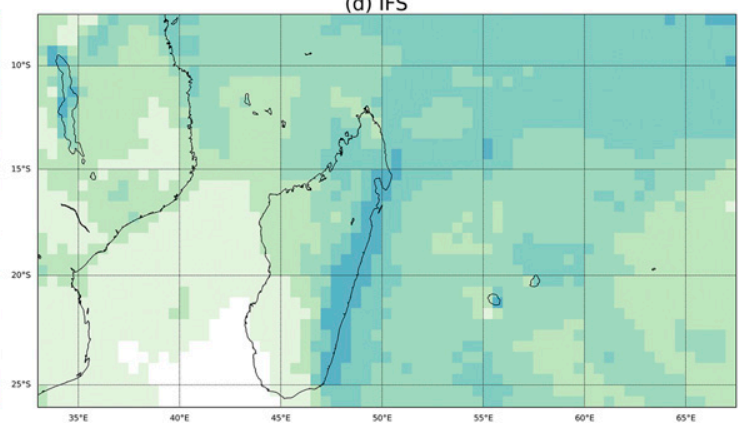

FIG. 7. Rainfall accumulation maps for the 10 -month period for $A R O M E_{\text {Indian }}$ domain on a common $0.5^{\circ}$-resolution grid; shown are data from satellite products (a) 3B42RT-V7 and (b) GSMAP and from models (c) AROME and (d) IFS.

and southwestern parts of the domain, and the more important accumulation over Greater Antilles. These patterns are consistent with the climatological ones depicted by Jury (2009). Both models reproduced these patterns, with a larger magnitude within AROME forecasts that appears closer to both references. Conversely, IFS tends to overestimate the annual amount of precipitation in the first two drier regions, and to underestimate the one over Hispaniola and Puerto Rico, providing on the whole a flatter field of rainfall accumulation than the satellite products or AROME ones.

- For the AROME ${ }_{\text {Indian }}$ domain, similar comments can be made on the accumulation maps shown in Fig. 7. From a large-scale perspective, two dry areas are consistently seen by the two satellite products over the Mozambique Channel and the southwestern part of Madagascar as well as the far east side of the domain. These patterns are reproduced by both models. Moreover, one can note of local effects like the high accumulations on the east coast of Madagascar that are depicted on the four maps, with the strongest maxima for AROME. Very local effects though, like large rainfall amounts that occur over La Réunion island as seen in section $4 \mathrm{a}(1)$, are poorly retrieved by the two satellite products, probably because of their coarse native resolution. Last, the northwestern region of Madagascar (Nosy Be area), which is depicted by satellite products as rainy, is accurately simulated by AROME but not by IFS. This region is a convergence zone for deep convection during the dry season and also subject to orographic heavy rain from spiral bands when a tropical cyclone develops over the Mozambique Channel (personal communication from the chief forecaster, Sébastien Langlade, of the Météo-France La Réunion Regional Centre).

- For the AROME $E_{\text {Caledonia }}$ domain shown on Fig. 8, a southwest-northeast gradient of rainfall accumulation is present in the two satellite products and also in the two models ouputs. As reported in Table 4, the maxima of AROME and IFS are very similar, respectively, of 2220 and $2201 \mathrm{~mm}$. These values are smaller than the maxima of GSMAP and 3B42RT-V7 (2820 and $2732 \mathrm{~mm}$ ).

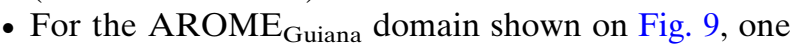
can note the very large differences of rainfall estimation over land between GSMAP and 3B42RT-V7, which makes the validation results difficult to interpret over this area. The common point between the four maps is the high rainfall accumulations along the coast due to local convection.

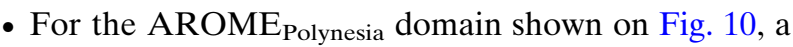
northwest-southeast gradient can be seen. Covering roughly one-fourth of the domain, an area of large rainfall accumulation in the southeast of the domain is coherently depicted by 3B42RT-V7, GSMAP, and IFS, but appears too weak in AROME. 
(a) 3B42RT-V7

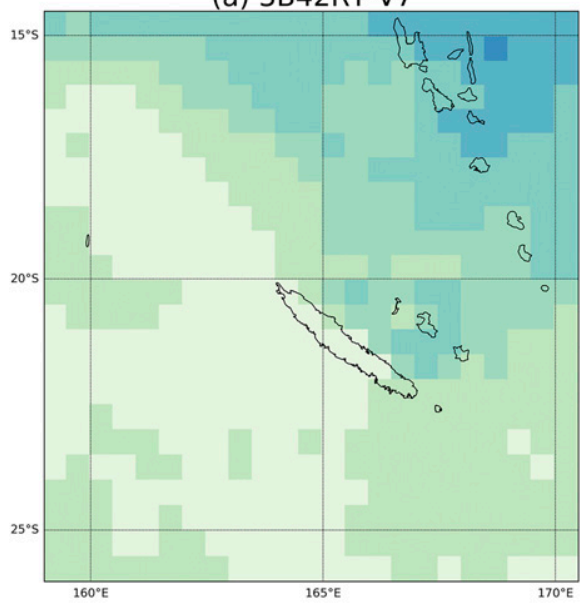

(b) GSMAP

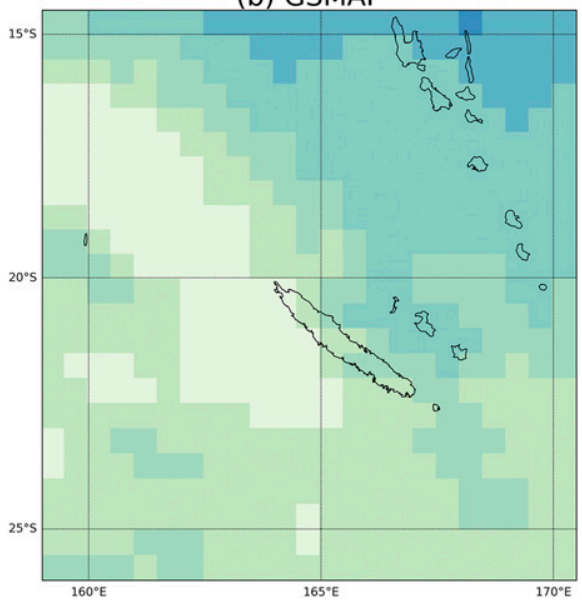

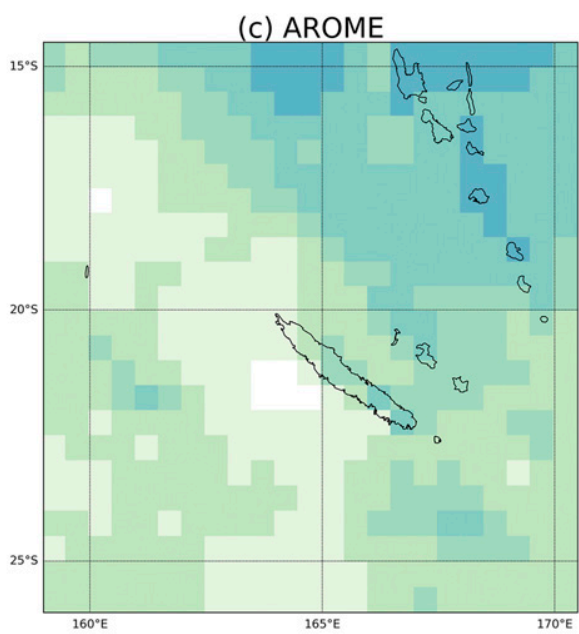

(d) IFS

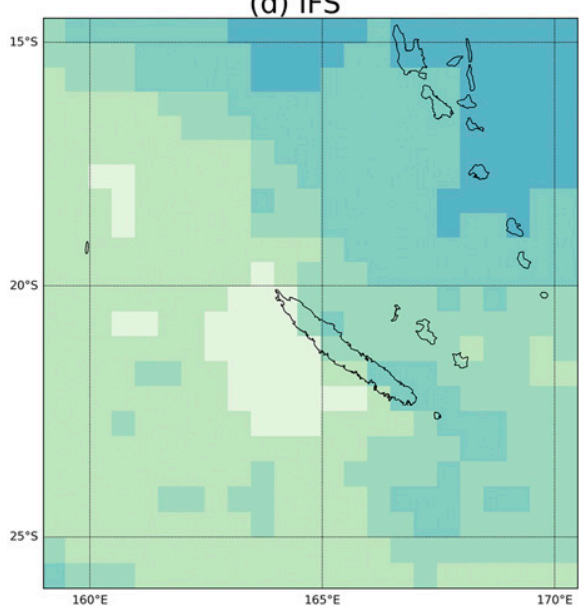

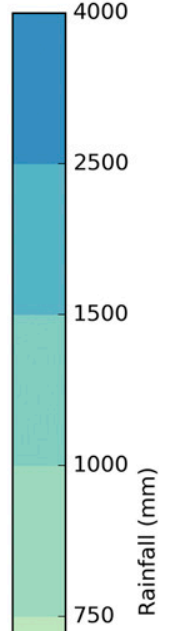

500

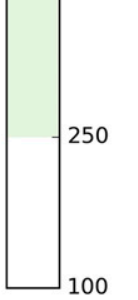

100

FIG. 8. Rainfall accumulation maps for the 10-month period for AROME $E_{\text {Caledonia }}$ domain on a common $0.5^{\circ}$ resolution grid; shown are data from satellite products (a) 3B42RT-V7 and (b) GSMAP and from models (c) AROME and (d) IFS.

Figure $5 \mathrm{c}$ objectively compares the rainfall accumulation variance among the products. The coefficient of determination computed between the 3B42RT-V7 and GSMAP product indicates that one product explains a large fraction of the variance of the other for the $\mathrm{AROME}_{\text {Antilles}}, \mathrm{AROME}_{\text {Indian, }}$, and $\mathrm{AROME} \mathrm{E}_{\text {Caledonia }}$ domains, with an $R^{2}$ value always above 0.75 and reaching 0.85 for the latter. The lowest consistency between the rainfall products for the $\mathrm{AROME}_{\text {Guiana }}$ domain leads to an $R^{2}$ smaller than 0.4 . For the $\mathrm{AROME}_{\text {Antilles }}$ and the AROME $\mathrm{Aaledonia}_{\text {domains, the }}$ model forecasts roughly explain $60 \%$ of the variance of the satellite products. The $R^{2}$ value reaches 0.8 when comparing IFS and GSMAP over the AROME $\mathrm{Caledonia}$ domain. At this stage, an apparent inconsistency appears between the realism of the AROME rainfall fields, as assessed subjectively at the beginning of this section, and the fact that they do not objectively explain a larger fraction of variance of the observations. The best example of this discrepancy is shown within the $\mathrm{AROME}_{\text {Antilles }}$ domain: AROME and IFS have very similar coefficients of determination (Fig. 5c), but subjectively the AROME field appears to be more realistic than the IFS one (Fig. 6). Actually, the patterns of rainfall are better depicted by AROME than IFS on a broad-scale comparison, but not necessarily on a pixel-to-pixel comparison. This is an indicator that the well-known double-penalty problem (Roberts and Lean 2008; Amodei and Stein 2009) for the evaluation of mesoscale rainfall forecasts may be also present at long evaluation time scales and coarse resolutions like the one under investigation in this section. This double-penalty problem was less noticeable in the previous section with ANTILOPE products, although the comparison was performed on a much finer scale. An explanation could be that because the majority of 


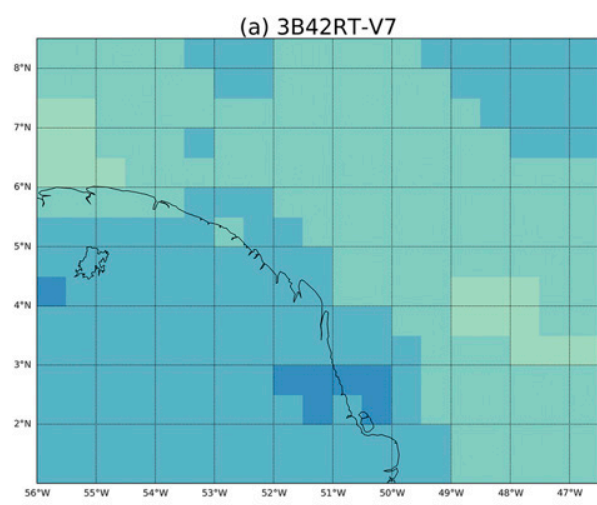

(b) GSMAP

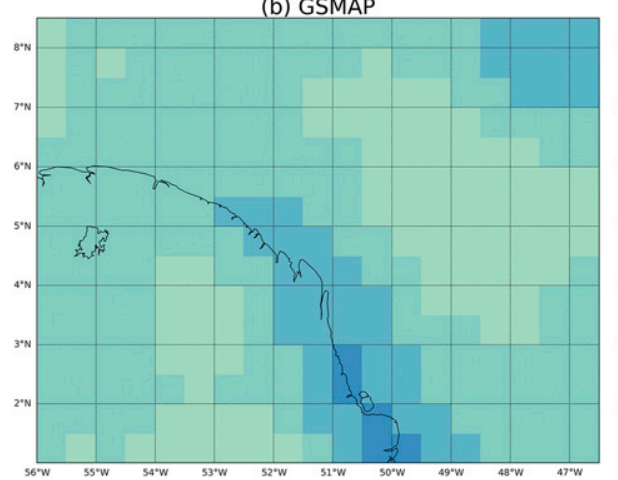

(c) AROME

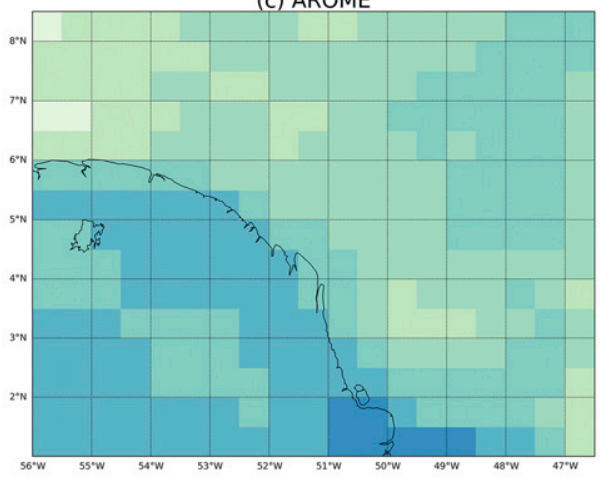

(d) IFS

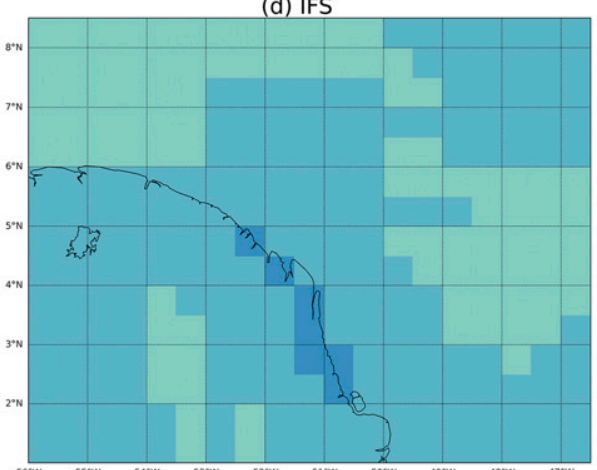

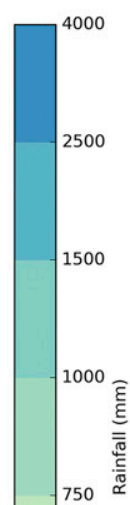

500

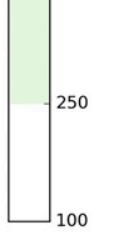

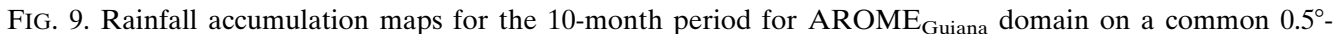
resolution grid; shown are data from satellite products (a) 3B42RT-V7 and (b) GSMAP and from models (c) AROME and (d) IFS.

rainfall patterns are being driven by orography on ANTILOPE domains, they are less subject to localization issues. The evaluation at the daily scale in the following section uses dedicated metrics to avoid the doublepenalty problem.

\section{b. Intercomparison at the daily scale}

In each of the comparisons presented below, distributions of daily rain accumulations either observed or forecasted are first intercompared to document the main features of each dataset. Then the FSS metric described in section $3 b$ is used to assess the rainfall variability in AROME and IFS forecasts.

\section{1) DAILY SCALE WITH RESPECT TO COMBINED RADAR/RAIN GAUGE PRODUCTS}

The daily accumulation histograms shown on Fig. 11 indicate a fair agreement between ANTILOPE, AROME, and IFS. Highly consistent conclusions, that are valid for the three geographical domains, can be made:

- AROME forecasts are characterized by a realistic number of no-rain samples with respect to the three ANTILOPE products. These no-rain situations are underestimated in the IFS forecasts.
- For a rain regime between 1 and $10 \mathrm{~mm} \mathrm{day}^{-1}$, there is an excess of samples (a lack) within the IFS forecasts (AROME forecasts). This lack of samples in the AROME forecasts is the strongest for the

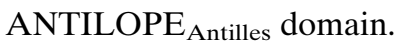

- Above $10-25 \mathrm{~mm}$ day $^{-1}$, the IFS forecasts underestimate the occurrence of rainfall; AROME starts to overestimate the occurrence of rainfall for accumulations larger than $100 \mathrm{~mm} \mathrm{day}^{-1}$ (note that above this threshold very few samples are available).

The fuzzy verification performed with the FSS metric, shown on Fig. 12, illustrates that as expected the models perform better for the smallest rainfall thresholds, and for larger rainfall accumulations, their performance degrades. For instance FSS for AROME ranges between 0.4 and 0.6 for a $0.1-\mathrm{mm}$ threshold, between 0.2 and 0.5 for a $3-\mathrm{mm}$ threshold, and decreases to 0.1 for the strongest rain threshold. With respect to IFS, the FSS values for AROME are significantly higher for most of the cases, as shown in the right column of Fig. 12, except for the 0.1- and 3-mm thresholds for the

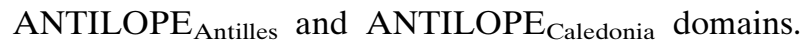
Over the ANTILOPE Indian $_{\text {domain, AROME forecasts }}$ perform significantly better than the IFS ones for all rain 
(a) 3B42RT-V7

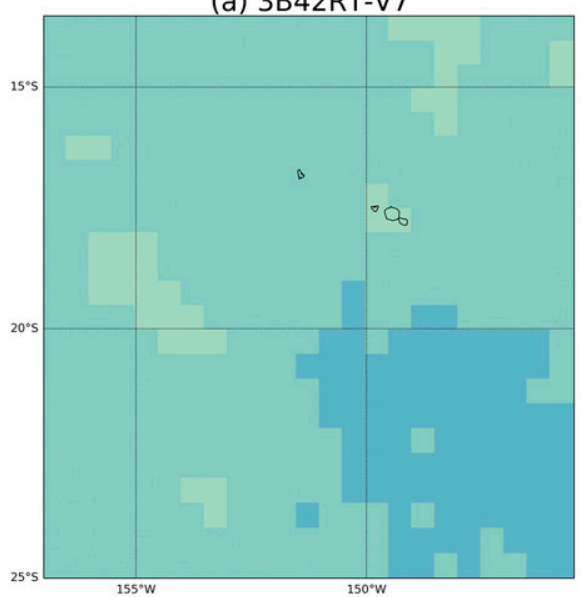

(b) GSMAP

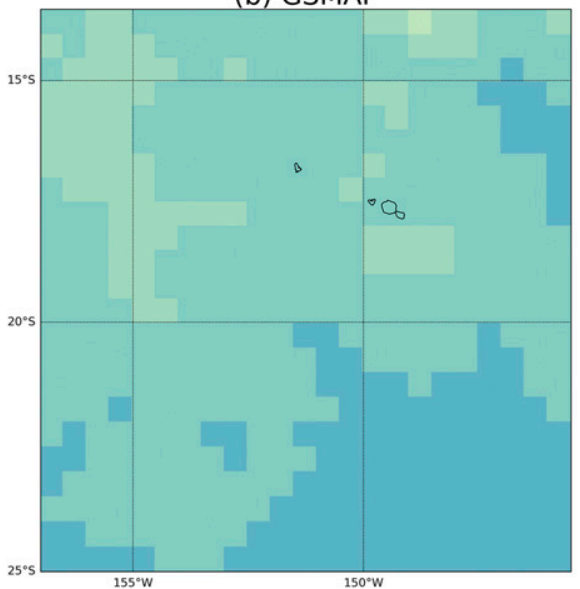

(c) AROME

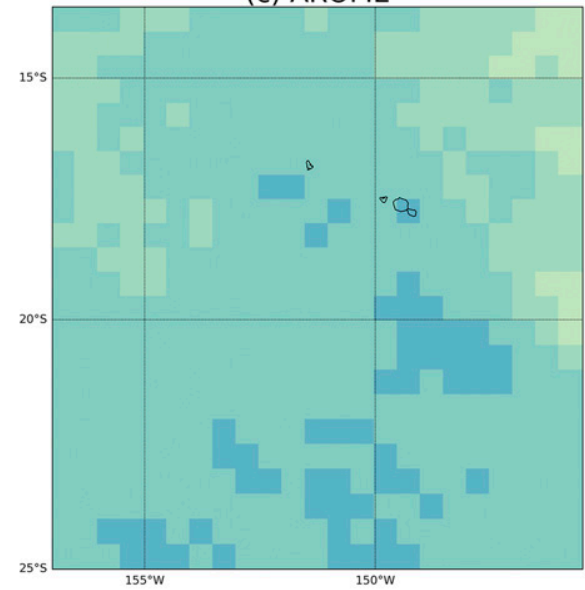

(d) IFS

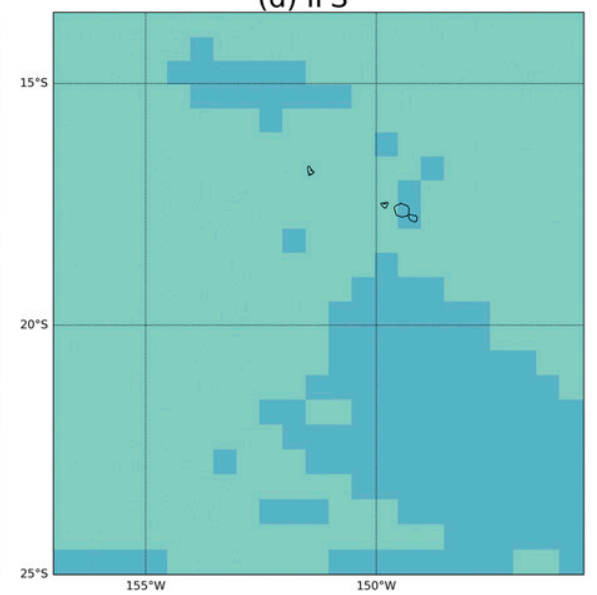

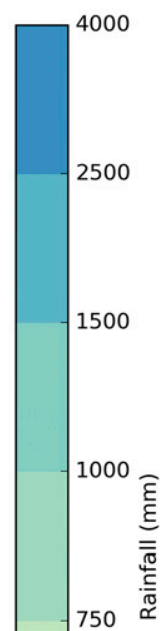

500

250

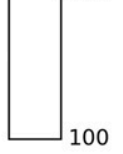

100

FIG. 10. Rainfall accumulation maps for the 10-month period for AROME $E_{\text {Polynesia }}$ domain on a common $0.5^{\circ}$ resolution grid; shown are data from satellite products (a) 3B42RT-V7 and (b) GSMAP and from models (c) AROME and (d) IFS.

thresholds, by roughly $10 \%$ for the small rain accumulations and up to $200 \%$ for the rain accumulations above $50 \mathrm{~mm}$. The same calculations have been performed for different neighborhood sizes (not shown) and do not affect the conclusions drawn before.

\section{2) DAILY SCALE WITH RESPECT TO SATELLITE RAINFALL PRODUCTS}

When performing the intercomparison over the five AROME domains with the two satellite precipitation products as reference (Fig. 13), one does note some similar features than at the finer kilometric scale:

- the number of AROME no-rain samples is closer to the two references than the IFS ones, across the five domains;

- within an intermediate rainfall regime between 1 and $10 \mathrm{~mm} \mathrm{day}^{-1}$, the occurrence of rainfall is overestimated for IFS and slightly less overestimated for AROME; and
- above $10 \mathrm{~mm} \mathrm{day}^{-1}$, the occurrence of rainfall is in general underestimated by the two models, with AROME being closer to the two references than IFS. Above $100 \mathrm{~mm} \mathrm{day}^{-1}$, the samples are very small and are not considered in the discussion.

The fractions skills scores computed for the full domains at the $0.5^{\circ}$ scale are characterized by a similar variability than at the kilometric scale over the ANTILOPE domains. In the left column of Fig. 14, one

TABLE 4. Maxima of rainfall accumulation ( $\mathrm{mm}$ ) over the full period on AROME domains for models and references.

\begin{tabular}{lcccc}
\hline \hline AROME domain & GSMAP & 3B42RT-V7 & AROME & IFS \\
\hline Antilles & 3573 & 2391 & 3067 & 2716 \\
Indian & 2865 & 3581 & 3238 & 2343 \\
Caledonia & 2594 & 2709 & 2220 & 2201 \\
Guiana & 2820 & 2732 & 3956 & 2701 \\
Polynesia & 2240 & 1850 & 1922 & 2077 \\
\hline
\end{tabular}


(a)

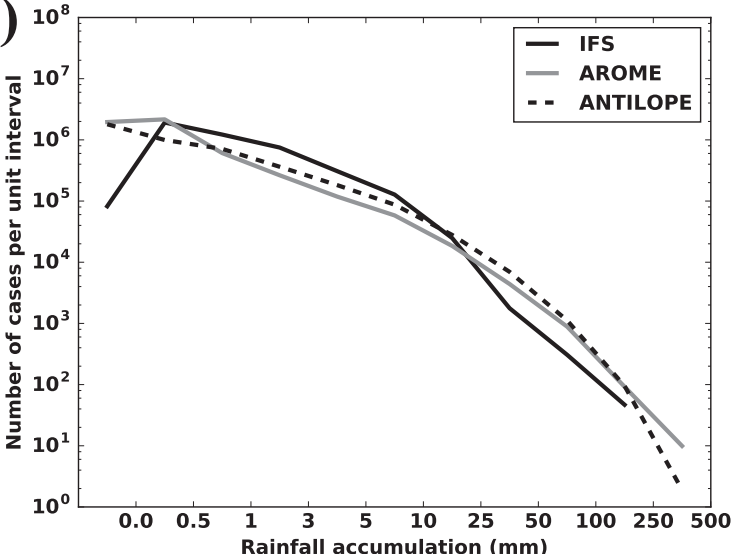

(b)

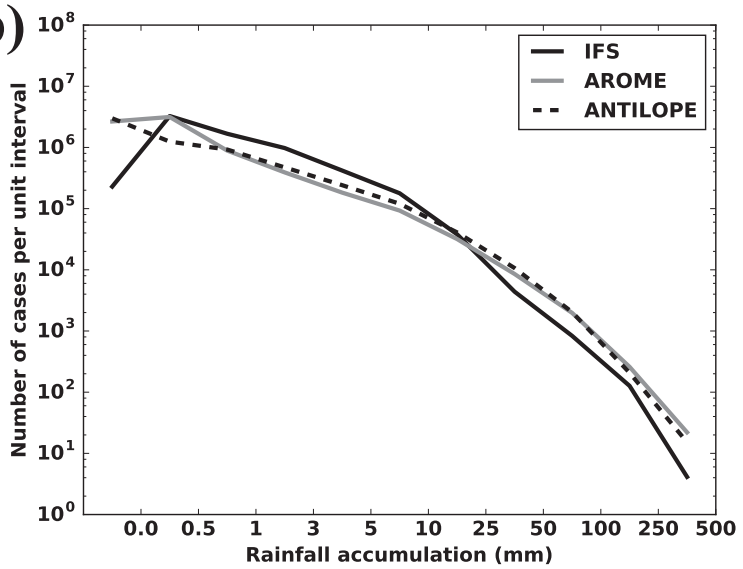

(c)

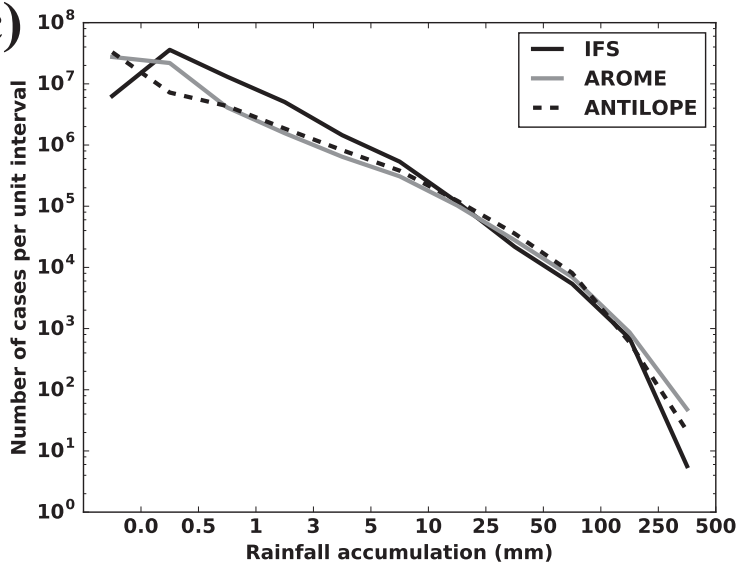

FIG. 11. Histograms of daily rain accumulations for the full 10month period. The number of samples has been normalized by each bin width, except for the first bin, corresponding to the absolute number of no-rain samples. Data for the ANTILOPE product and for IFS and AROME models, for the following 1-km-

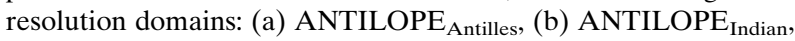
and (c) ANTILOPE $E_{\text {Caledonia. }}$

can see that for the $0.1 \mathrm{~mm} \mathrm{day}^{-1}$ threshold, the FSS ranges between 0.55 and 0.8 depending on the domain, with the best value for AROME $E_{\text {Guiana. }}$ For the $50 \mathrm{~mm} \mathrm{day}^{-1}$ threshold, the FSS ranges between much lower values of 0.1 and 0.3 . While using either 3B42RTV7 or GSMAP as the reference does slightly change the FSS values with lower values on average for GSMAP (e.g., Fig. 14b), the absolute variations from one geographical domain to another are well characterized by the two products.

The differences of FSS between AROME and IFS shown in the right column of Fig. 14 indicate consistent conclusions when compared with the ANTILOPE product:

- For the 0.1-mm threshold, AROME forecasts are more realistic in the sense of FSS higher by $10-20 \%$ with respect to the IFS.

- For a rain regime from 1 to $10 \mathrm{~mm} \mathrm{day}^{-1}$ (only $3 \mathrm{~mm} \mathrm{day}^{-1}$ is shown), for which the occurrence of rainfall is overestimated by IFS, this latter model does provide better rainfall forecasts over some of the domains. The FSS differences range between $-5 \%$ and $-15 \%$ and are statistically significant at the $95 \%$ confidence level for four domains when 3B42RT-V7 is used as reference. When GSMAP is used as reference, the differences are statistically significant only for the $\mathrm{AROME}_{\text {Indian }}$ and the $\mathrm{AROME}_{\text {Caledonia }}$ domains.

- Then for higher rainfall accumulation thresholds (only 25 and $50 \mathrm{~mm}$ day $^{-1}$ are shown), AROME FSS values are significantly better than the IFS ones, up to $100 \%$ for $50 \mathrm{~mm} \mathrm{day}^{-1}$ over the $\mathrm{AROME}_{\text {Antilles }}$ domain. The only domain for which no statistically significant difference can be found is $A R O M E_{\text {Caledonia }}$.

Overall, the results found in this section are quite consistent with subjective expectations of a convectivescale model: when compared to a larger-scale model, the performance of AROME is not necessarily better on a point-by-point basis, even on very long time scales like 10-month accumulations. But when using dedicated metrics taking into account the misplacements of mesoscale features, then AROME forecasts are characterized by much better scores than the IFS, in particular for distinguishing rain and no-rain situations as well as for intense precipitation situations. The following and last section will illustrate these behaviors through three particular situations.

\section{Three case studies}

Before drawing conclusions, and in addition to the comprehensive statistics shown before, some case studies are shown in this section; the aim is to illustrate how the two models AROME and IFS, although sharing almost the same initial conditions at the beginning of each run, can differ on a daily basis. To pick just a few 
(a) $010 \mathrm{~km}$ neighborhood / $0.1 \mathrm{~mm}$ rain threshold

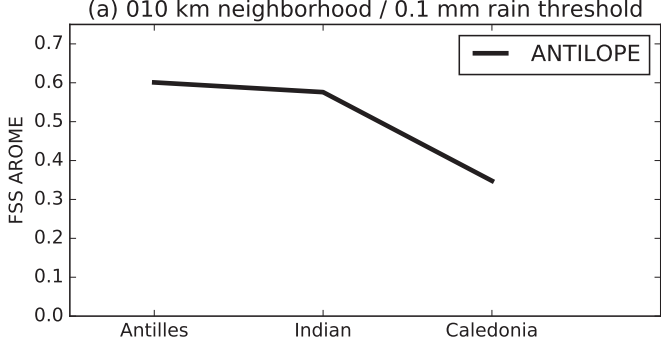

(b) $010 \mathrm{~km}$ neighborhood $/ 3.0 \mathrm{~mm}$ rain threshold

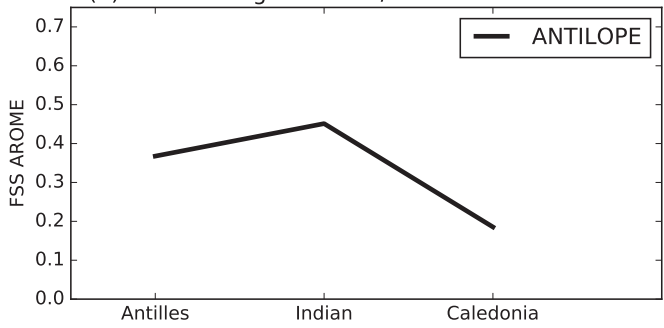

(c) $010 \mathrm{~km}$ neighborhood $/ 25.0 \mathrm{~mm}$ rain threshold

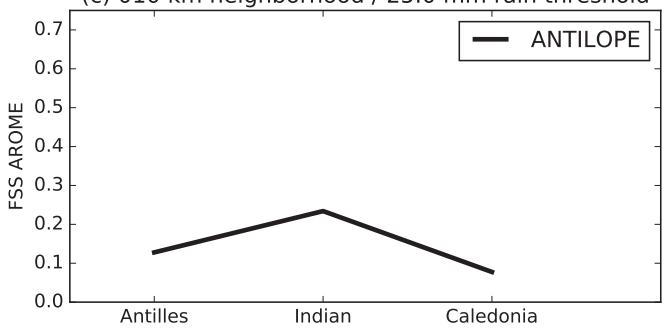

(d) $010 \mathrm{~km}$ neighborhood $/ 50.0 \mathrm{~mm}$ rain threshold

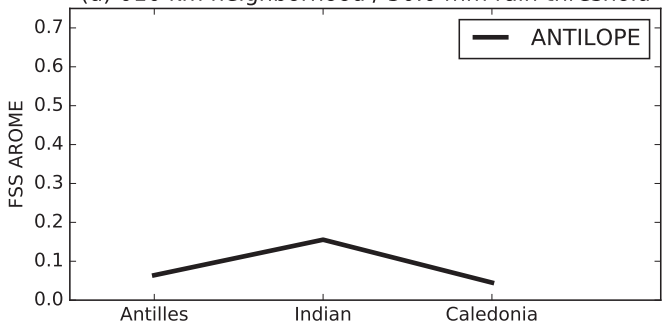

(e) $010 \mathrm{~km}$ neighborhood / $0.1 \mathrm{~mm}$ rain threshold

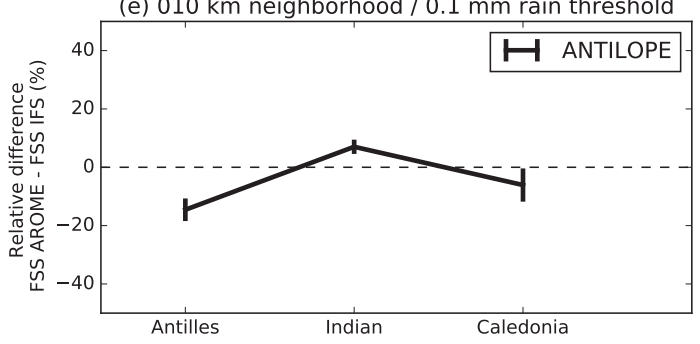

(f) $010 \mathrm{~km}$ neighborhood $/ 3.0 \mathrm{~mm}$ rain threshold

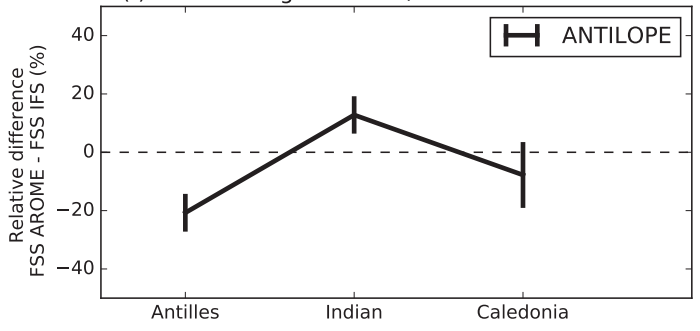

(g) $010 \mathrm{~km}$ neighborhood $/ 25.0 \mathrm{~mm}$ rain threshold

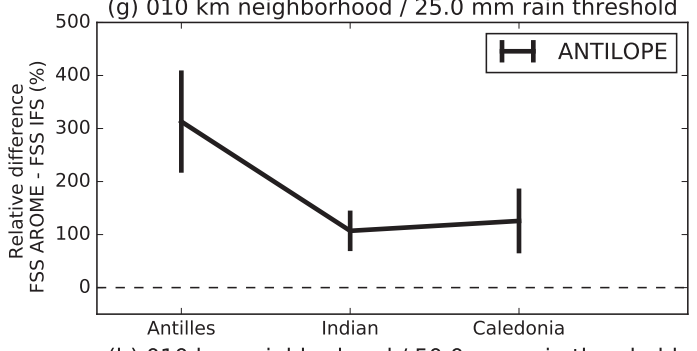

(h) $010 \mathrm{~km}$ neighborhood $/ 50.0 \mathrm{~mm}$ rain threshold

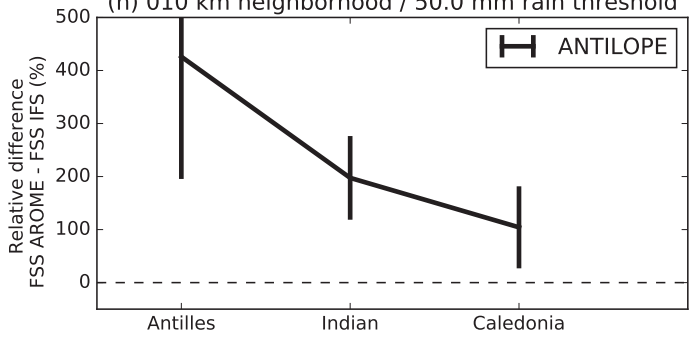

FIG. 12. (left) Daily fractions skill score of the AROME forecasts with respect to the ANTILOPE products for the three ANTILOPE domains at 1-km resolution, averaged over the full 10-month period. (right) Relative difference $(\%)$ of the daily fractions skill score of AROME and IFS, both with respect to the ANTILOPE products, averaged over the full 10-month period. Each row corresponds to a given rain threshold of daily rainfall for the score calculation: (a),(e) 0.1, (b),(f) 3.0, (c),(g) 25.0, and (d),(h) $50.0 \mathrm{~mm}$. The FSS values are represented for a single neighborhood of $10 \mathrm{~km}$. The error bars are computed as standard errors on the mean with a $95 \%$ confidence level.

situations among the large amount of forecasts available in this study, the month of March 2017 had been arbitrarily selected, and for this month an interesting situation has been chosen for the three AROME domains where ANTILOPE products are available. This allows us to compare the forecasts at a very fine scale, which is representative of their use by the forecasters.

\section{a. The 24- $h$ forecast from 0000 UTC 9 March 2017, ANTILOPE $E_{\text {Antilles }}$ domain}

Figure 15 shows that a cold front from the north brings unusual rainfall for that season over the northern part of the Lesser Antilles. The ANTILOPE product (Fig. 15a) locates for each island the most intense rainfall over the main summits (maxima of $205 \mathrm{~mm}$ on Guadeloupe and $42 \mathrm{~mm}$ on Martinique), while norain regions are tiny and very few. The AROME forecast (Fig. 15b) is able to localize accurately the heavy rain places, with, respectively, underestimated maxima of 70 and $12 \mathrm{~mm}$, but overestimates the size of the dry areas. Conversely, the IFS forecast (Fig. 15c) does not provide any no-rain region, and its highest amounts of rain (also underestimated, with, respectively, maxima of 37 and $20 \mathrm{~mm}$ ) are localized on the 

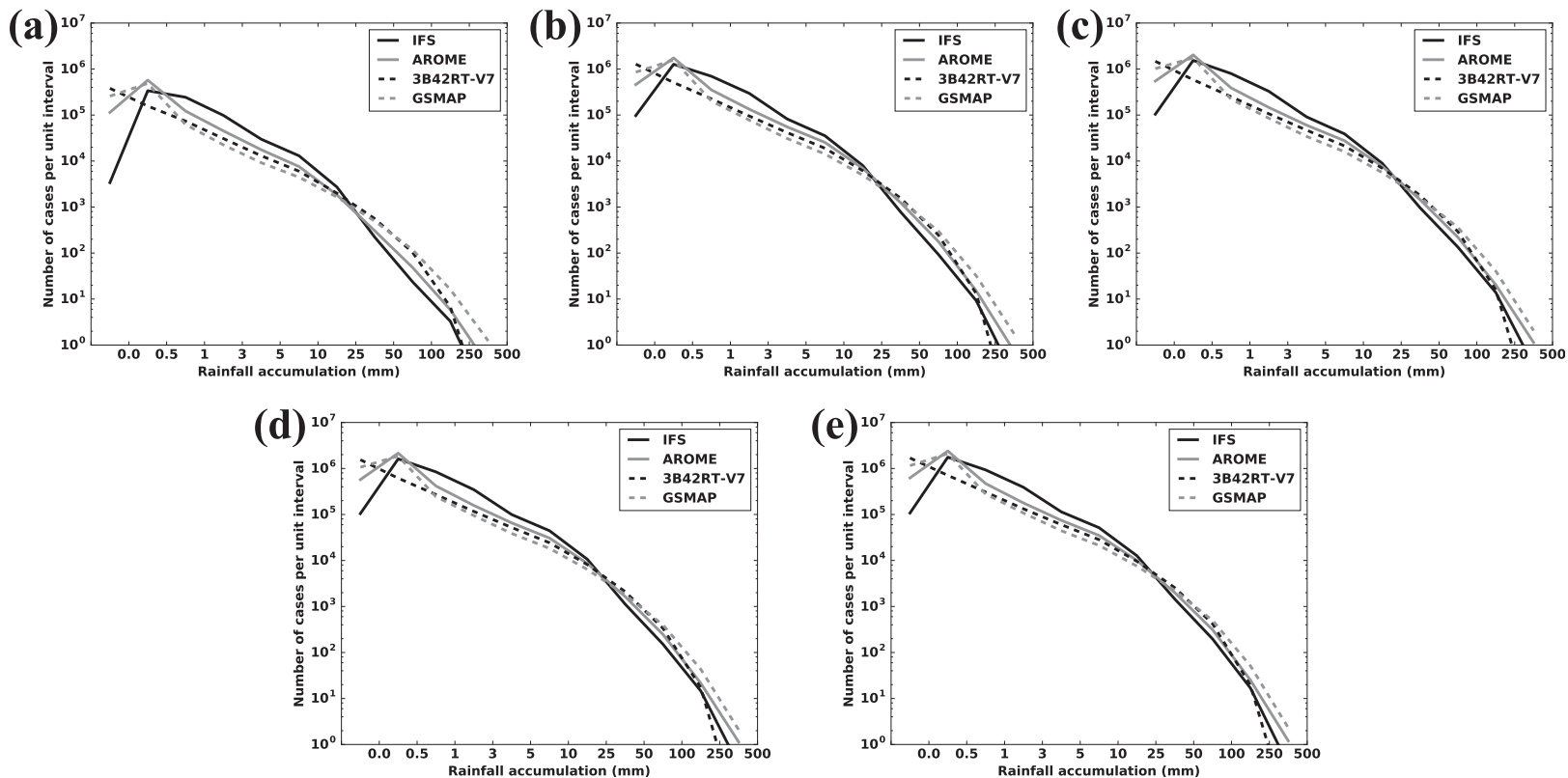

FIG. 13. Histograms of daily rain accumulations for the full 10-month period. The number of samples has been normalized by each bin width, except for the first bin, corresponding to the absolute number of no-rain samples. Data for 3B42RT-V7 and GSMAP products and

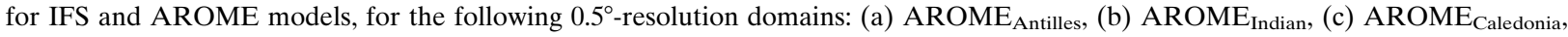
(d) AROME $_{\text {Guiana }}$, and (e) AROME $E_{\text {Polynesia. }}$

shore, upstream from the mountains. The better localization of the heavy rainfall by AROME on that particular situation can be related to Figs. $12 \mathrm{~g}$ and $12 \mathrm{~h}$, showing that AROME has better FSS values than IFS for rainfall above $25 \mathrm{~mm} \mathrm{day}^{-1}$ on the ANTILOPE Antilles domain.

\section{b. The 24-h forecast from 0000 UTC 16 March 2017, $A N T I L O P E_{\text {Indian }}$ domain}

Figure 16 shows a common situation for the wet season, with advection from the northeast of warm and humid air. It leads to generalized rain over La Réunion, with the highest amounts (up to $278 \mathrm{~mm}$ ) on the east side of the highest summits as shown by the ANTILOPE product (Fig. 16a). One can also note that the situation on the west side is quite contrasted, with a dry zone on the southwest side and rain elsewhere. The AROME forecast (Fig. 16b) is able to depict these patterns (with a maximum of $187 \mathrm{~mm}$ ), while the IFS one (Fig. 16c) shows the same behavior as for the previous situation on the ANTILOPE $E_{\text {Antilles }}$ domain: on the east side of La Réunion, the highest rainfalls are underestimated (maximum of $43 \mathrm{~mm}$ ) and located on the shore and not on the summits. Moreover an unrealistic dry area appears on the northwest side. This situation can be related to Fig. 3c, showing a better coefficient of determination for AROME compared to IFS for the ANTILOPE $_{\text {Indian }}$ domain.

\section{c. The 24-h forecast from 0000 UTC 16 March 2017, ANTILOPE $E_{\text {Caledonia domain }}$}

Figure 17 depicts the same day as for the previous domain, and the studied situation is also quite usual for the season. In an easterly advection of warm and humid air, convection occurs in several regions of the domain, and not only over mountains. As indicated by the ANTILOPE product (Fig. 17a), the most intense (up to $216 \mathrm{~mm}$ ) and widespread rain occurs on the eastern and the southern parts of Grande Terre, between Lifou and Grande Terre, and north of Grande Terre. There are large dry areas over land and ocean during this $24 \mathrm{~h}$ period. The AROME forecast (Fig. 17b), reaching a maximum of rain of $152 \mathrm{~mm}$, is able to reproduce all these patterns, but the rainy region north of Grande Terre. Contrary to the two previous situations, the IFS forecast (Fig. 17c) reaches a maximum of rain very similar to AROME one $(159 \mathrm{~mm})$, but it shows heavy rain only on the very southern part of Grande Terre, missing all the other patterns. In addition, there is virtually no dry region over the ocean, which can be related to Fig. 11c, showing than the number of samples of norain events is underestimated by IFS compared to both ANTILOPE and AROME.

Only through these three particular situations, one can see that some general conclusions drawn in the previous sections are consistent with what can be observed on a day-to-day basis. Among them, the most 

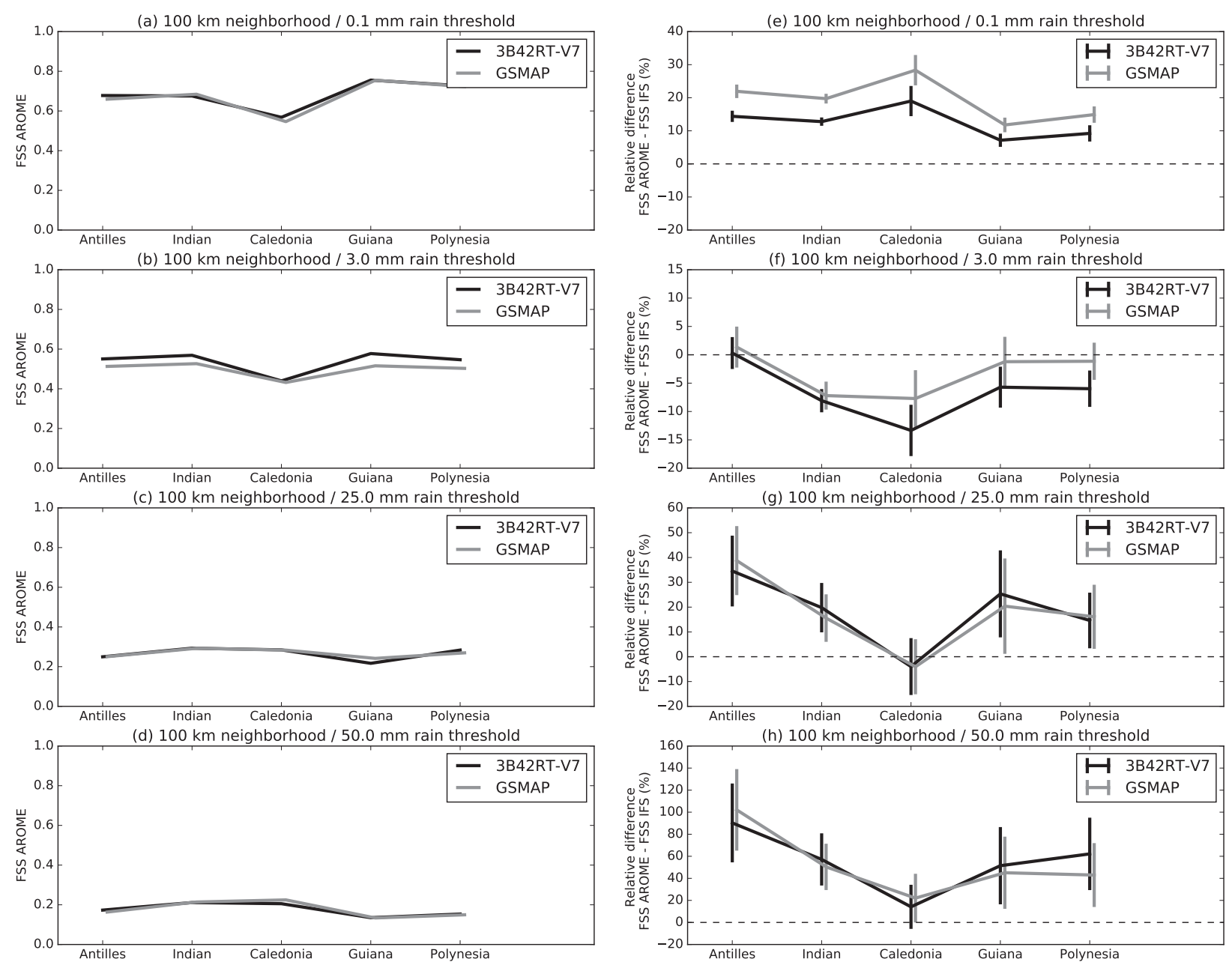

FIG. 14. (left) Daily fractions skill score of the AROME forecasts with respect to the 3B42RT-V7 and the GSMAP products for the five AROME domains at the $0.5^{\circ}$ resolution, averaged over the full 10 -month period. (right) Relative difference (\%) of the daily fractions skill score of AROME and IFS, both with respect to the 3B42RT-V7 and the GSMAP products, averaged over the full 10-month period. Each row corresponds to a given rain threshold of daily rainfall for the score calculation: (a),(e) 0.1, (b),(f) 3.0, (c), (g) 25.0, and (d), (h) 50.0 mm. The FSS values are represented for a single neighborhood of $100 \mathrm{~km}$. The error bars are computed as standard errors on the mean with a $95 \%$ confidence level.

visible one is probably the tendency of IFS to localize the highest rainfall upstream of mountains, while AROME simulates its most intense rainfall over these mountains, as observed. These features seem to be very common according to Météo-France forecasters.

\section{Summary and discussion}

In this study, precipitation forecasts from the AROME-OM system have been assessed with respect to the IFS model to which AROME is coupled both for initialization and lateral boundary conditions. For conducting the comparisons, several datasets across the five geographical domains have been used. At the local scale over several islands, the ANTILOPE product
(Météo-France), combining radar and rain gauge data, has been used for a finescale validation. In addition, for comparing AROME and IFS forecasts over the full AROME domains, two satellite products have been used: the 3B42RT-V7 product (NASA) and the GSMAP product (JAXA).

Overall, this intercomparison over a 10-month period shows consistent signals across regions, scales, and rain regimes. The added value of the AROME-OM system was quantified for no-rain events and for rain accumulations larger than $10 \mathrm{~mm} \mathrm{day}^{-1}$, both at the local scale with ANTILOPE products and at a larger scale with the satellite products. This study also strengthens with objective metrics the subjective evaluation performed by Météo-France forecasters in the French overseas 

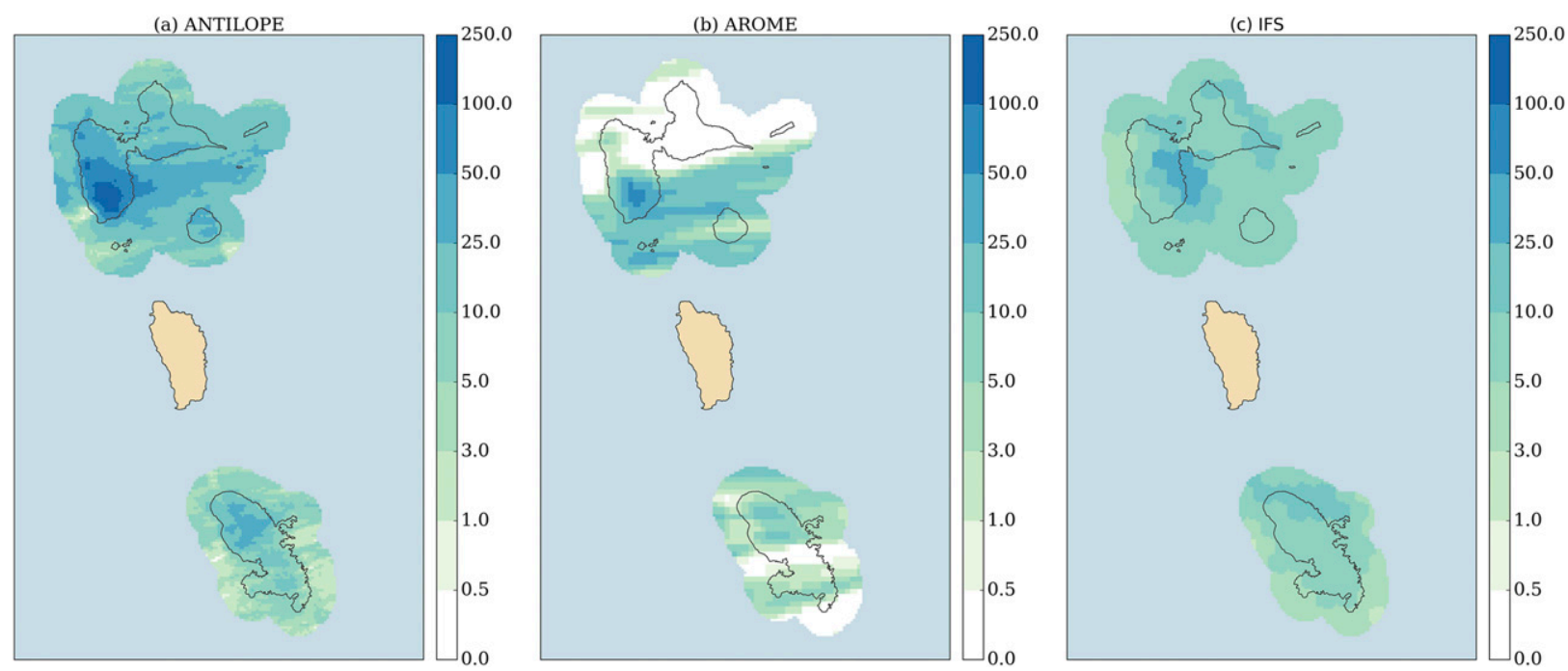

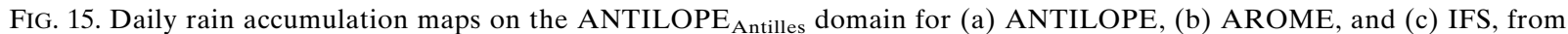
0000 UTC 9 Mar to 0000 UTC 10 Mar 2017. Model forecasts correspond to the $+24-\mathrm{h}$ range and are plotted on the ANTILOPE 1-km-resolution grid.

territories on the ability of AROME to predict strong rainfall events with a good degree of realism, in particular in the case of orographically driven rainfall. This study also confirms some weaknesses of the AROME-OM system that will need to be further investigated. In particular, an intermediate rainfall regime between roughly 1 and $10 \mathrm{~mm} \mathrm{day}^{-1}$ was found to be less well forecasted by AROME than by IFS (5\%$15 \%$ smaller FSS).

Several perspectives to further improve the AROME$\mathrm{OM}$ system are currently under investigation. To address the weakness to forecast the $1-10 \mathrm{~mm} \mathrm{day}^{-1}$ regime, research focuses on the AROME physics, in particular a finer tuning of its microphysics scheme and making its shallow-convection scheme precipitating, and on the
AROME dynamics, like for instance an increased horizontal resolution of $1.3 \mathrm{~km}$ like AROME-France. The evaluation of these potential improvements on rainfall will have to be refined, for instance by assessing subdaily time scales. Another interesting perpective for evaluation, especially with the growing use of the AROME model for climate projections, will be to assess the performance of the AROME-OM system according to the season and to the ENSO phase. This kind of study requires us to focus on a longer period of time and on each domain individually; as shown for instance by Sullivan et al. (2019), the properties of organized convection in the tropics and its associated rainfall according to the ENSO phase is region dependant. On a longer term, the goal is to provide the best possible guidance to
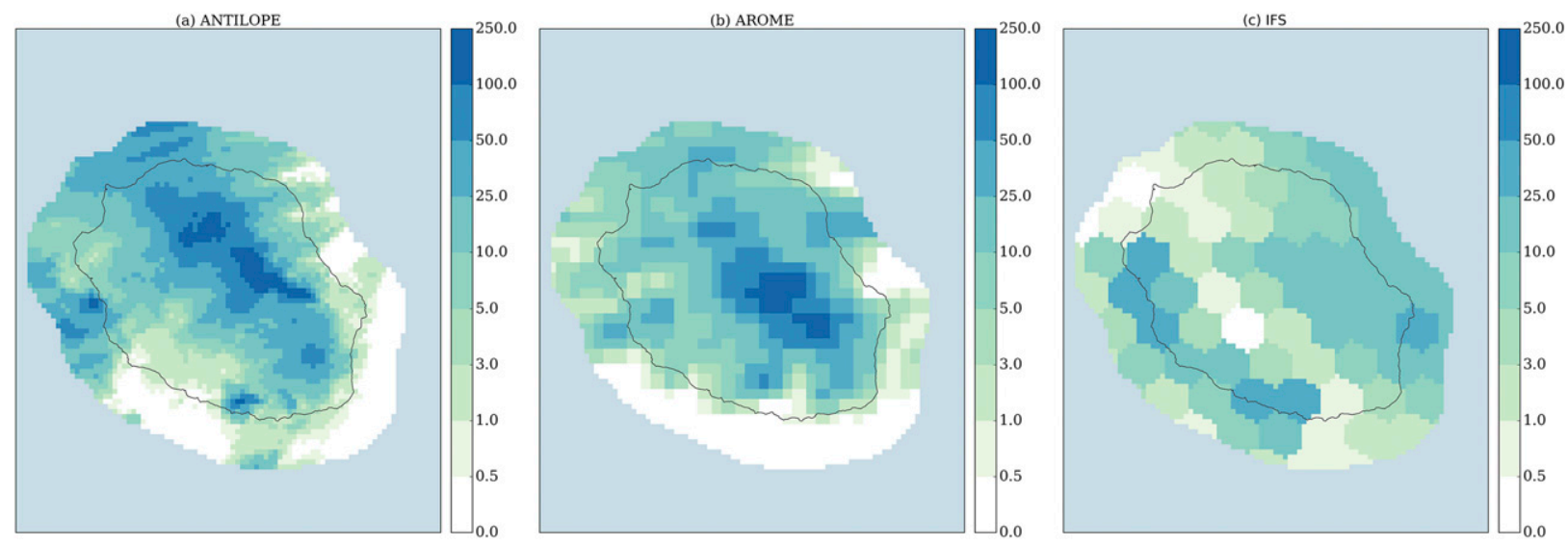

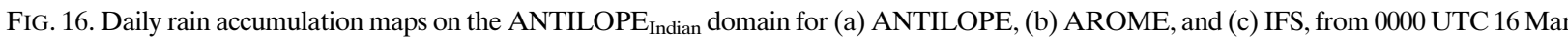
to 0000 UTC 17 Mar 2017. Model forecasts correspond to the $+24-\mathrm{h}$ range and are plotted on the ANTILOPE 1-km-resolution grid. 

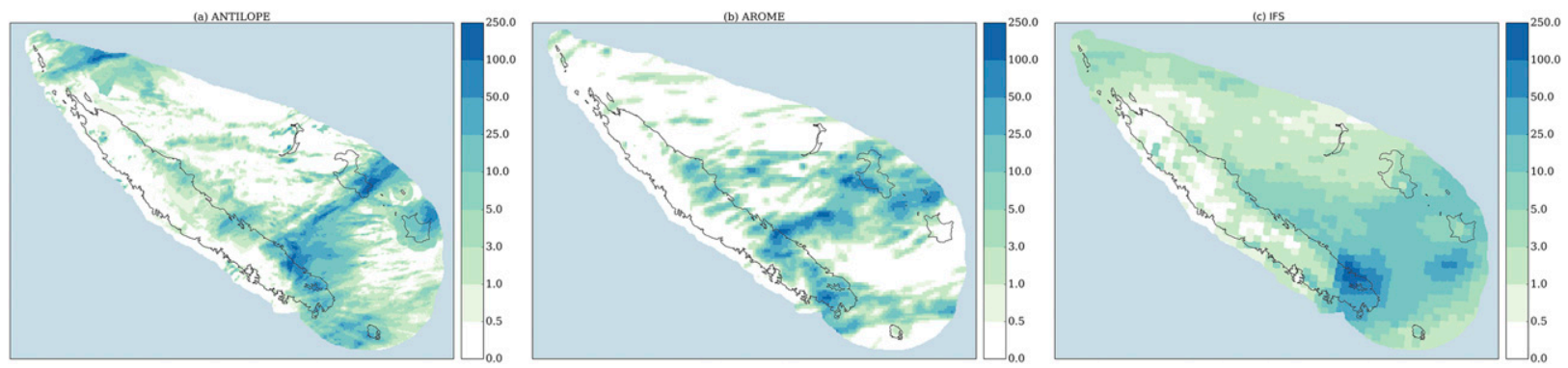

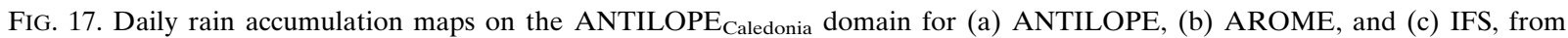
0000 UTC 16 Mar to 0000 UTC 17 Mar 2017. Model forecasts correspond to the +24 -h range and are plotted on the ANTILOPE 1-kmresolution grid.

forecasters and the best possible improvement on objective scores, while keeping the complexity and the required resources for the maintenance of the AROMEOM system at a sustainable cost. Keeping these general considerations in mind, several additional components for the AROME-OM system will be evaluated, like the potential benefit of data assimilation and a more realistic ocean coupling, based on a 3D ocean model. Perhaps more importantly, an ensemble prediction system will be studied, which will address the quantification of the forecast uncertainty and could eventually provide access to the overseas forecasters to mesoscale probabilistic products.

Acknowledgments. The authors thank the two reviewers and the editor for their great recommendations that helped to improve the manuscript, and also Claude Fischer for all his valuable advice during the writing of this article.

\section{REFERENCES}

Amodei, M., and J. Stein, 2009: Deterministic and fuzzy verification methods for a hierarchy of numerical models. Meteor. Appl., 16, 191-203, https://doi.org/10.1002/met.101.

Baldauf, M., A. Seifert, J. Förstner, D. Majewski, M. Raschendorfer, and T. Reinhardt, 2011: Operational convective-scale numerical weather prediction with the COSMO model: Description and sensitivities. Mon. Wea. Rev., 139, 3887-3905, https://doi.org/ 10.1175/MWR-D-10-05013.1.

Bechtold, P., N. Semane, P. Lopez, J.-P. Chaboureau, A. Beljaars, and N. Bormann, 2014: Representing equilibrium and nonequilibrium convection in large-scale models. J. Atmos. Sci., 71, 734-753, https://doi.org/10.1175/JAS-D-13-0163.1.

Bernardet, L., and Coauthors, 2015: Community support and transition of research to operations for the Hurricane Weather Research and Forecasting Model. Bull. Amer. Meteor. Soc., 96, 953-960, https://doi.org/10.1175/BAMS-D-13-00093.1.

Bloom, S. C., L. L. Takacs, A. M. da Silva, and D. Ledvina, 1996: Data assimilation using incremental analysis updates. Mon. Wea. Rev., 124, 1256-1271, https://doi.org/10.1175/1520-0493(1996) 124<1256:DAUIAU $>2.0 . \mathrm{CO} ; 2$.

Brousseau, P., Y. Seity, D. Ricard, and J. Léger, 2016: Improvement of the forecast of convective activity from the AROME-France system. Quart. J. Roy. Meteor. Soc., 142, 2231-2243, https:// doi.org/10.1002/qj.2822.

Champeaux, J. L., O. Laurantin, B. Mercier, F. Mounier, P. Lassegues, and P. Tabary, 2011: Quantitative precipitation estimations using rain gauges and radar networks: Inventory and prospects at Meteo-France. WMO Joint Meeting of CIMO Expert Team on Operational Remote Sensing and CBS Expert Team on Surface-Based Remote Sensing Observations, Geneva, Switzerland, World Meteorological Organization, 5-9.

Clark, P., N. Roberts, H. Lean, S. P. Ballard, and C. CharltonPerez, 2016: Convection-permitting models: A step-change in rainfall forecasting. Meteor. Appl., 23, 165-181, https://doi.org/ 10.1002/met.1538.

Cuxart, J., P. Bougeault, and J.-L. Redelsperger, 2000: A turbulence scheme allowing for mesoscale and large-eddy simulations. Quart. J. Roy. Meteor. Soc., 126, 1-30, https://doi.org/ 10.1002/qj.49712656202.

Davis, C., and Coauthors, 2008: Prediction of landfalling hurricanes with the Advanced Hurricane WRF Model. Mon. Wea. Rev., 136, 1990-2005, https://doi.org/10.1175/2007MWR2085.1.

Done, J., C. A. Davis, and M. Weisman, 2004: The next generation of NWP: Explicit forecasts of convection using the weather research and forecasting (WRF) model. Atmos. Sci. Lett., 5, 110-117, https://doi.org/10.1002/asl.72.

Ebert, E. E., 2008: Fuzzy verification of high-resolution gridded forecasts: A review and proposed framework. Meteor. Appl., 15, 51-64, https://doi.org/10.1002/met.25.

Fouquart, Y., and B. Bonnel, 1980: Computations of solar heating of the earth's atmosphere-A new parameterization. Beitr. Phys. Atmos., 53, 35-62.

Gosset, M., M. Alcoba, R. Roca, S. Cloché, and G. Urbani, 2018: Evaluation of TAPEER daily estimates and other GPM-era products against dense gauge networks in West Africa, analysing ground reference uncertainty. Quart. J. Roy. Meteor. Soc., 144, 255-269, https://doi.org/10.1002/qj.3335.

Huffman, G. J., and Coauthors, 2007: The TRMM Multisatellite Precipitation Analysis (TMPA): Quasi-global, multiyear, combined-sensor precipitation estimates at fine scales. J. Hydrometeor., 8, 38-55, https://doi.org/10.1175/JHM560.1.

Jury, M. R., 2009: An intercomparison of observational, reanalysis, satellite, and coupled model data on mean rainfall in the Caribbean. J. Hydrometeor., 10, 413-430, https://doi.org/10.1175/ 2008JHM1054.1.

Kubota, T., and Coauthors, 2007: Global precipitation map using satellite-borne microwave radiometers by the GSMaP project: Production and validation. IEEE Trans. Geosci. Remote Sens., 45, 2259-2275, https://doi.org/10.1109/TGRS.2007.895337. 
Laurantin, O., 2008: Antilope: Hourly rainfall analysis merging radar and rain gauge data. Proc. Int. Symp. on Weather Radar and Hydrology Conf. 2008, Grenoble, France, Laboratoire d'étude des Transferts en Hydrologie et Environnement (LTHE), 2-8.

Lean, H. W., P. A. Clark, M. Dixon, N. M. Roberts, A. Fitch, R. Forbes, and C. Halliwell, 2008: Characteristics of highresolution versions of the Met Office Unified Model for forecasting convection over the United Kingdom. Mon. Wea. Rev., 136, 3408-3424, https://doi.org/10.1175/ 2008MWR2332.1.

Lellouche, J.-M., and Coauthors, 2018: Recent updates to the Copernicus Marine Service global ocean monitoring and forecasting real-time $1 / 12^{\circ}$ high-resolution system. Ocean Sci., 14, 1093-1126, https://doi.org/10.5194/os-14-1093-2018.

Levizzani, V., and Coauthors, 2018: The activities of the international precipitation working group. Quart. J. Roy. Meteor. Soc., 144, 3-15, https://doi.org/10.1002/qj.3214.

Masson, V., and Coauthors, 2013: The SURFEXv7.2 land and ocean surface platform for coupled or offline simulation of earth surface variables and fluxes. Geosci. Model Dev., 6, 929960, https://doi.org/10.5194/gmd-6-929-2013.

Mlawer, E. J., S. J. Taubman, P. D. Brown, M. J. Iacono, and S. A. Clough, 1997: Radiative transfer for inhomogeneous atmospheres: RRTM, a validated correlated-k model for the longwave. J. Geophys. Res., 102, 16 663-16 682, https://doi.org/ 10.1029/97JD00237.

Montroty, R., F. Rabier, S. Westrelin, G. Faure, and N. Viltard, 2008: Impact of wind bogus and cloud- and rain-affected SSM/I data on tropical cyclone analyses and forecasts. Quart. J. Roy. Meteor. Soc., 134, 1673-1699, https://doi.org/ 10.1002/qj.308.

Morcrette, J.-J., 1991: Radiation and cloud radiative properties in the European Centre for Medium Range Weather Forecasts forecasting system. J. Geophys. Res., 96, 9121-9132, https:// doi.org/10.1029/89JD01597.

Murphy, A. H., 1995: The coefficients of correlation and determination as measures of performance in forecast verification. Wea. Forecasting, 10, 681-688, https://doi.org/10.1175/1520-0434(1995) $010<0681$ :TCOCAD $>2.0 . \mathrm{CO} ; 2$.

Noilhan, J., and S. Planton, 1989: A simple parameterization of land surface processes for meteorological models. Mon. Wea. Rev., 117, 536-549, https://doi.org/10.1175/1520-0493(1989) 117<0536:ASPOLS >2.0.CO;2.

Pergaud, J., V. Masson, S. Malardel, and F. Couvreux, 2009: A parameterization of dry thermals and shallow cumuli for mesoscale numerical weather prediction. Bound.-Layer Meteor., 132, 83-106, https://doi.org/10.1007/s10546-009-9388-0.
Pinty, J.-P., and P. Jabouille, 1998: A mixed-phased cloud parameterization for use in a mesoscale non-hydrostatic model: Simulations of a squall line and of orographic precipitation. Preprints, Conf. on Cloud Physics, Everett, WA, Amer. Meteor. Soc., 217-220.

Roberts, N. M., and H. W. Lean, 2008: Scale-selective verification of rainfall accumulations from high-resolution forecasts of convective events. Mon. Wea. Rev., 136, 78-97, https://doi.org/ 10.1175/2007MWR2123.1.

Samson, G., H. Giordani, G. Caniaux, and F. Roux, 2009: Numerical investigation of an oceanic resonant regime induced by hurricane winds. Ocean Dyn., 59, 565-586, https://doi.org/10.1007/ s10236-009-0203-8.

Seity, Y., P. Brousseau, S. Malardel, G. Hello, P. Bénard, F. Bouttier, C. Lac, and V. Masson, 2011: The AROME-France convectivescale operational model. Mon. Wea. Rev., 139, 976-991, https:// doi.org/10.1175/2010MWR3425.1.

Sullivan, S. C., K. A. Schiro, C. Stubenrauch, and P. Gentine, 2019: The response of tropical organized convection to El Niño warming. J. Geophys. Res. Atmos., 124, 8481-8500, https:// doi.org/10.1029/2019JD031026.

Termonia, P., and Coauthors, 2018: The ALADIN system and its canonical model configurations AROME CY41T1 and ALARO CY40T1. Geosci. Model Dev., 11, 257-281, https:// doi.org/10.5194/gmd-11-257-2018.

van den Hurk, B. J. J. M., P. Viterbo, A. C. M. Beljaars, and A. K. Betts, 2000: Offline validation of the ERA40 surface scheme. ECMWF Tech Memo. 295, 42 pp., http://www.ecmwf.int/sites/ default/files/elibrary/2000/12900-offline-validation-era40-surfacescheme.pdf.

Váňa, F., P. Bénard, J.-F. Geleyn, A. Simon, and Y. Seity, 2008: Semi-Lagrangian advection scheme with controlled damping: An alternative to nonlinear horizontal diffusion in a numerical weather prediction model. Quart. J. Roy. Meteor. Soc., 134 523-537, https://doi.org/10.1002/qj.220.

Weisman, M. L., C. Davis, W. Wang, K. W. Manning, and J. B. Klemp, 2008: Experiences with 0-36-h explicit convective forecasts with the WRF-ARW model. Wea. Forecasting, 23, 407-437, https://doi.org/10.1175/2007WAF2007005.1.

Woodhams, B. J., C. E. Birch, J. H. Marsham, C. L. Bain, N. M. Roberts, and D. F. A. Boyd, 2018: What is the added value of a convection-permitting model for forecasting extreme rainfall over tropical East Africa? Mon. Wea. Rev., 146, 2757-2780, https://doi.org/10.1175/MWR-D-17-0396.1.

Zhu, K., and Coauthors, 2018: Evaluation of real-time convectionpermitting precipitation forecasts in China during the 2013 2014 summer season. J. Geophys. Res. Atmos., 123, 1037-1064, https://doi.org/10.1002/2017JD027445. 